\title{
Effects of operation parameters on performances of stratum ventilation for heating mode
}

Zhang, Sheng; Lin, Zhang; Ai, Zhengtao; Wang, Fenghao; Cheng, Yong; Huan, Chao

Published in:

Building and Environment

Link to article, DOI:

10.1016/j.buildenv.2018.11.001

Publication date:

2019

Document Version

Peer reviewed version

Link back to DTU Orbit

Citation (APA):

Zhang, S., Lin, Z., Ai, Z., Wang, F., Cheng, Y., \& Huan, C. (2019). Effects of operation parameters on performances of stratum ventilation for heating mode. Building and Environment, 148, 55-66.

https://doi.org/10.1016/j.buildenv.2018.11.001

\section{General rights}

Copyright and moral rights for the publications made accessible in the public portal are retained by the authors and/or other copyright owners and it is a condition of accessing publications that users recognise and abide by the legal requirements associated with these rights.

- Users may download and print one copy of any publication from the public portal for the purpose of private study or research.

- You may not further distribute the material or use it for any profit-making activity or commercial gain

- You may freely distribute the URL identifying the publication in the public portal 


\section{Effects of operation parameters on performances of stratum ventilation for heating mode}

Article in Building and Environment · November 2018

DOI: 10.1016/j.buildenv.2018.11.001

\section{CITATIONS}

16

6 authors, including:

Sheng Zhang

City University of Hong Kong

29 PUBLICATIONS 337 CITATIONS

SEE PROFILE

2.T.Ai

Hunan University

47 PUBLICATIONS 671 CITATIONS

SEE PROFILE

Some of the authors of this publication are also working on these related projects:

PhD candidate View project

Call for paper---Energy and Built Environment, International Journal View project
Zhang Lin

City University of Hong Kong

176 PUBLICATIONS 4,478 CITATIONS

SEE PROFILE

Feng-hao Wang

29 PUBLICATIONS 282 CITATIONS

SEE PROFILE 


\section{Accepted Manuscript}

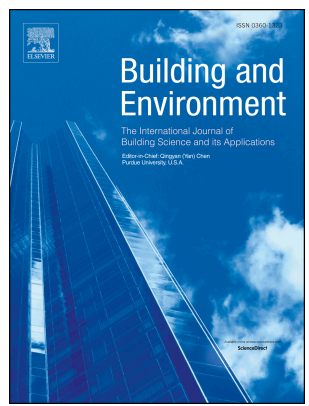

Effects of operation parameters on performances of stratum ventilation for heating mode

Sheng Zhang, Zhang Lin, Zhengtao Ai, Fenghao Wang, Yong Cheng, Chao Huan

PII: $\quad$ S0360-1323(18)30689-9

DOI: $\quad$ https://doi.org/10.1016/j.buildenv.2018.11.001

Reference: BAE 5794

To appear in: Building and Environment

Received Date: 27 August 2018

Revised Date: 1 November 2018

Accepted Date: 2 November 2018

Please cite this article as: Zhang S, Lin Z, Ai Z, Wang F, Cheng Y, Huan C, Effects of operation parameters on performances of stratum ventilation for heating mode, Building and Environment (2018), doi: https://doi.org/10.1016/j.buildenv.2018.11.001.

This is a PDF file of an unedited manuscript that has been accepted for publication. As a service to our customers we are providing this early version of the manuscript. The manuscript will undergo copyediting, typesetting, and review of the resulting proof before it is published in its final form. Please note that during the production process errors may be discovered which could affect the content, and all legal disclaimers that apply to the journal pertain. 


\title{
Effects of Operation Parameters on Performances of Stratum Ventilation for Heating Mode
}

Sheng Zhang ${ }^{1}$, Zhang $\mathrm{Lin}^{2}$, Zhengtao $\mathrm{Ai}^{3}$, Fenghao $\mathrm{Wang}^{4}$, Yong Cheng ${ }^{5,6 *}$, Chao $\operatorname{Huan}^{7} *$

${ }^{1}$ Department of Architecture and Civil Engineering, City University of Hong Kong, Kowloon, Hong Kong, China

${ }^{2}$ Division of Building Science and Technology, City University of Hong Kong, Hong Kong, China

${ }^{3}$ International Centre for Indoor Environment and Energy, Department of Civil Engineering, Technical University of Denmark, Denmark

${ }^{4}$ School of Human Settlements and Civil Engineering, Xi'an Jiaotong University, Xi'an, China

${ }^{5}$ National Centre for International Research of Low-carbon and Green Buildings, Ministry of Science \& Technology, Chongqing University, Chongqing, China

${ }^{6}$ Key Laboratory of Three Gorges Reservoir Region's Eco-Environment, Ministry of Education, Chongqing University, Chongqing, China

${ }^{7}$ School of Energy and Resource, Xi' an University of Science and Technology, Xi' an, China

*Corresponding author. Tel.: +86 2365120771; fax: +86 2365126160; E-mail: yongcheng6@cqu.edu.cn

*Corresponding author. E-mail: huanchao111@163.com

\begin{abstract}
Stratum ventilation is more energy-efficient as compared with mixing ventilation for cooling applications. However, due to the short development history of stratum ventilation, few studies on its heating applications are available. The heating operation of stratum ventilation is different from the cooling operation due to the distinct airflow patterns. This study comprehensively investigates the effects of the operation parameters on heating performances of stratum ventilation, using experimentally validated Computational Fluid Dynamics (CFD) simulations. The operation parameters include controllable supply vane angle, supply airflow rate and
\end{abstract}


supply air temperature, and uncontrollable outdoor weather condition. The ventilation performance indices adopt local mean age of air (LMAA), $\mathrm{CO}_{2}$ removal efficiency (CRE), Predicted Mean Vote (PMV), vertical air temperature difference between head and ankle levels $(\Delta T)$ and energy utilization coefficient (EUC). By evaluating the individual effects of the operation parameters on the ventilation performances, the relative importance (i.e., relative sensitivity) of the operation parameters for each ventilation performance is identified. By comparing the individual effects and combined effects of the operation parameters on the ventilation performances, it is found that the variations of LMAA, CRE, PMV, $\Delta T$ and EUC caused by the combined effects can be accounted by the corresponding most important operation parameters by $86.5 \%, 85.6 \%, 78.8 \%, 65.7 \%$ and $70.2 \%$ respectively. Moreover, the outdoor weather condition does not significantly affect LMAA, CRE and EUC, but can transfer PMV and $\Delta T$ to discomfort level. Lastly, to facilitate heating applications of stratum ventilation, the constant-air-volume system is recommended and a simplified operation strategy is proposed.

Keywords: Stratum ventilation; Heating; Operation Performances; Sensitivity analysis; Individual effects; Combined effects

\section{Nomenclature}

$C \quad \mathrm{CO}_{2}$ concentration (ppm) $\mathrm{CO}_{2}$ concentration in

$C_{\mathrm{b}} \quad$ breathing level (ppm)

$C_{\mathrm{e}}$ $\mathrm{CO}_{2}$ concentration in exit air

$C_{\mathrm{s}} \quad \mathrm{CO}_{2}$ concentration in supply

air (ppm)

D Hydraulic diameter (m)

$i \quad$ the $i^{\text {th }}$ input

$I P_{b c} \quad$ input of base case

L Exhaled airflow rate $(\mathrm{L} / \mathrm{h})$
$V_{\mathrm{s}} \quad$ supply airflow rate $\left(\mathrm{m}^{3} / \mathrm{s}\right)$

$V A_{\mathrm{s}} \quad$ supply vane angle $\left(^{\circ}\right)$

$x_{i} / \bar{x} \quad$ original/normalized value

$x_{\max }$ maximal/ minimal original value of $/ x_{\min } \quad$ design parameter

$\triangle I P \quad$ change in the input

$\triangle O P \quad$ change in the output

$\Delta T \quad$ vertical air temperature difference between head and ankle levels $\left({ }^{0} \mathrm{C}\right)$

\section{Abbreviations}




\begin{tabular}{|c|c|c|c|}
\hline$O P_{b c}$ & output of base case & CFD & Computational Fluid Dynamics \\
\hline$R^{2}$ & coefficient of determination & CRE & $\mathrm{CO}_{2}$ removal efficiency \\
\hline$T_{\mathrm{e}}$ & exit air temperature $\left({ }^{0} \mathrm{C}\right)$ & EUC & energy utilization coefficient \\
\hline$T_{\mathrm{o}}$ & $\begin{array}{l}\text { air temperature in occupied } \\
\text { zone }\left({ }^{0} \mathrm{C}\right)\end{array}$ & $\mathrm{IC}$ & influence coefficient \\
\hline$T_{\mathrm{s}}$ & supply air temperature $\left({ }^{0} \mathrm{C}\right)$ & LMAA & local mean age of air \\
\hline$T_{\mathrm{w}}$ & $\begin{array}{l}\text { inside surface temperature } \\
\text { of exterior envelope }\left({ }^{0} \mathrm{C}\right)\end{array}$ & PMV & Predicted Mean Vote \\
\hline TI & Turbulence intensity (\%) & RSS & root sum square \\
\hline
\end{tabular}

\section{Introduction}

\subsection{Background and context}

Air distributions are widely used for conditioning indoor environment to provide quality air and thermal comfort [1]. Stratum ventilation directly supplies conditioned air into the occupied zone from the side walls/columns [2]. For cooling applications, compared with mixing ventilation, stratum ventilation can more energy-efficiently create a healthy and comfortable indoor environment [3, 4]. Experiments confirmed that the thermally neutral temperature of stratum ventilation was approximately $2.5^{\circ} \mathrm{C}$ higher than that of mixing ventilation [5]. Lin et al. [6] found that for cooling an office, a classroom and a retail shop in Hong Kong, compared with mixing ventilation, stratum ventilation reduced the annual energy consumption of the air conditioning system by at least $44.37 \%$ whilst achieving comparable indoor environment quality. Particularly, the elevated thermally neutral temperature can help to improve the energy performance of the solar-driven cooling systems for low-energy buildings [7-9]. However, due to the short development history of stratum ventilation (less than 15 years), few studies on stratum ventilation for heating applications have been carried out [10]. 


\subsection{Previous work}

Existing studies of stratum ventilation focus on cooling applications, because stratum ventilation was initially proposed to accommodate the elevated room air temperatures for cooling applications [2]. Regarding the operation of stratum ventilation for cooling applications, Huan et al. [11] experimentally investigated the effects of the outdoor weather condition, supply airflow rate and supply air temperature on $\mathrm{CO}_{2}$ removal efficiency (CRE), Predicted Mean Vote (PMV) and energy efficiency. Using the experimentally validated CFD simulations, Tian et al. [12] confirmed that increasing the supply air temperature from $19^{\circ} \mathrm{C}$ to $21^{\circ} \mathrm{C}$ could reduce the local mean age of air (LMAA) for improving inhaled air quality. Zhang et al. [13] proposed to use the supply air and exit air conditions to inform the operation of stratum ventilation conveniently. The optimal room air temperature was identified by targeting at the desired PMV and maximizing the energy saving simultaneously [14]. The room air temperature could be maintained at the identified optimal value by using the multi-node model under steady states $[15,16]$, or using the heat removal efficiency based control method under dynamic states [17]. For thermal comfort improvement, Shao et al. [18] and Zhang et al. [19] proposed to control the supply air temperature and supply airflow rate to accommodate different thermal preferences. For targeted indoor air quality, Cheng et al. [20] proposed a method to accurately control the $\mathrm{CO}_{2}$ concentration in the breathing zone by coupling the mass conservation laws and $\mathrm{CO}_{2}$ removal efficiency in the breathing zone.

Stratum ventilation also has potentials for heating applications for two reasons [4, 21]. Firstly, it directly supplies warm air to the occupied zone by configuring the supply terminal(s) at the side walls/columns slightly above the head of occupants [2]. The high air velocity of stratum ventilation helps the supply air to efficiently reach the occupied zone for thermal comfort [22]. Secondly, the exit terminals can be configured at a low level of the room to avoid the short-circuiting of warm supply air and thus improve the ventilation efficiency [23]. Since stratum ventilation has been 
proven to have high ventilation efficiency in cooling applications [4], its heating applications are urgent to be investigated. So that stratum ventilation with high ventilation efficiency can be used for climate regions where heating is also required.

The operation of stratum ventilation for heating applications can be more complex than that for cooling applications. For cooling applications, since the cool supply air tends to flow downwards into the occupied zone, the supply vane angle is typically fixed at zero with a horizontal initial momentum of the supply air [10]. However, for heating applications, the supply vane angle should be appropriately controlled to generate a downward initial momentum of the supply air. So that the upward thermal buoyancy of the warm supply air can be overwhelmed. Otherwise, the warm supply air would flow into the upper zone without entering the occupied zone, resulting in a low ventilation efficiency [21]. Moreover, the effects of the other three operation parameters (i.e., the supply airflow rate, supply air temperature and outdoor weather condition) on the ventilation performances for heating applications would be different from those for cooling applications, due to the distinct airflow patterns between the heating and cooling applications [24].

\subsection{Aim of this study}

This study aims to comprehensively evaluate the effects of the four operation parameters on indoor air quality, thermal comfort and energy efficiency of stratum ventilation for heating applications. Based on the analyses of the individual effects and combined effects of these operation parameters on ventilation performances, a control strategy is proposed to simplify the operation of stratum ventilation for heating applications. Since stratum ventilation is applicable to small- to medium-sized rooms [2], this study is conducted for a typical office configuration using CFD simulations. Experiments on stratum ventilation for heating applications are conducted to validate the CFD simulations. 


\section{Methodology}

\subsection{Evaluation indices of ventilation performances}

A comprehensive evaluation of ventilation performances is conducted: LMAA and CRE representing indoor air quality, PMV and vertical air temperature difference between head and ankle levels $(\Delta T)$ indicating overall and local thermal comfort respectively, and energy utilization coefficient (EUC) indicating energy efficiency [4, 11, 20]. LMAA is the average lifetime of air at a particular location and gives an indication of the "freshness" of air [4]. A smaller LMAA is more preferred. $\mathrm{CO}_{2}$ is a widely used surrogate of indoor air quality [23, 25]. A larger CRE (Equation 1) indicates a higher ventilation efficiency and thereby improved air quality $[1,11,26]$. When calculating LMAA and CRE, the breathing zone is concerned for inhaled air quality (i.e., the height of $1.1 \mathrm{~m}$ above the floor for seated occupants). Regarding thermal comfort, PMV has been confirmed by subjective surveys to be applicable to stratum ventilation [27]. PMV at the height of $1.1 \mathrm{~m}$ (for seated occupants) is calculated for thermal comfort evaluation [17, 27]. PMV should be limited between -0.5 and 0.5 for overall thermal comfort [28]. For PMV calculation, the typical winter clothing level (i.e., $1.0 \mathrm{clo}$ ) and the near-sedentary activity level in an office (i.e., 1.1 met) are used, and the relative humidity is set to be $50 \%$ [28]. The detailed calculation of PMV can refer to ASHRAE 55 [28]. $\Delta T$ is the air temperature difference between the heights of $1.1 \mathrm{~m}$ and $0.1 \mathrm{~m}$ above the floor (for seated occupants), and is acceptable below $3^{\circ} \mathrm{C}$ for local thermal comfort [28]. It is noted that although draft is also a main concern for local thermal comfort, it is not considered in this study because the preliminary analysis shows that draft rating of stratum ventilation under heating is generally less than $20 \%$ which is thermally acceptable [21, 29]. EUC is defined as the ratio of the difference between the supply air temperature and exit air temperature to the difference between the supply air temperature and air temperature in the occupied zone (Equation 2) [21]. The definition of the occupied zone is given by Awbi [30]. A larger EUC indicates that the supply air is more efficiently used for 
warming the occupied zone, resulting in a higher energy efficiency.

$$
\begin{gathered}
C R E=\frac{C_{\mathrm{e}}-C_{\mathrm{s}}}{C_{\mathrm{b}}-C_{\mathrm{s}}} \\
E U C=\frac{T_{\mathrm{s}}-T_{\mathrm{e}}}{T_{\mathrm{s}}-T_{\mathrm{o}}}
\end{gathered}
$$

where $C R E$ is the $\mathrm{CO}_{2}$ removal efficiency; $E U C$ is the energy utilization coefficient; $C_{\mathrm{b}}, C_{\mathrm{e}}$ and $C_{\mathrm{s}}$ are the $\mathrm{CO}_{2}$ concentrations at the breathing zone, in exit air and in supply air respectively (ppm); $T_{\mathrm{e}}, T_{\mathrm{S}}$ and $T_{\mathrm{o}}$ are the temperatures of exit air, supply air and air in the occupied zone respectively $\left({ }^{0} \mathrm{C}\right)$.

\subsection{Experiment}

A test chamber simulating a typical office with dimensions of $3.9 \mathrm{~m}$ (length) $\times 2.9 \mathrm{~m}$ (width) $\times 2.6 \mathrm{~m}$ (height) is set up, as shown in Figure 1. The chamber is located at $\mathrm{Xi}$ 'an Jiaotong University. The experiment is conducted in this chamber in winter when the outdoor air temperature is generally between $-1{ }^{\circ} \mathrm{C}$ and $8^{\circ} \mathrm{C}$. Stratum ventilation is used to condition its indoor thermal environment. The warm air is supplied from a rectangular double grill diffuser $(0.2 \mathrm{~m} \times 0.17 \mathrm{~m})$ located at $1.3 \mathrm{~m}$ height of the right wall, and then exhausted via a perforated diffuser $(0.6 \mathrm{~m} \times 0.6 \mathrm{~m})$ located on the ceiling. A rectangular thermal manikin with dimensions of $0.4 \mathrm{~m} \times 0.35$ $\mathrm{m} \times 1.2 \mathrm{~m}$ is applied to simulate an occupant. The rectangular thermal manikin is one of the common representation methods of the occupant for both CFD simulations and experiments of the indoor thermal environment $[2,11,19]$. It has been experimentally confirmed that the rectangular thermal manikin is adequate to simulate the interaction between the occupant and indoor thermal environment [22]. The heat of this thermal manikin is generated by three $25 \mathrm{~W}$ light bulbs [31]. $\mathrm{CO}_{2}$ is introduced via a small hole of $10 \mathrm{~mm}$ at the height of $1.1 \mathrm{~m}$ to simulate exhalation from the occupant, with a constant flow rate of $18 \mathrm{~L} / \mathrm{h}$ [30]. A box with dimensions of $0.4 \mathrm{~m} \times 0.4 \mathrm{~m} \times 0.4 \mathrm{~m}$, which is heated by three $60 \mathrm{~W}$ light bulbs, is located on the table to simulate a computer [31]. The test chamber is illuminated by 2 sets of lights, with a total of $2 \times$ $72 \mathrm{~W}$ electrical power. 


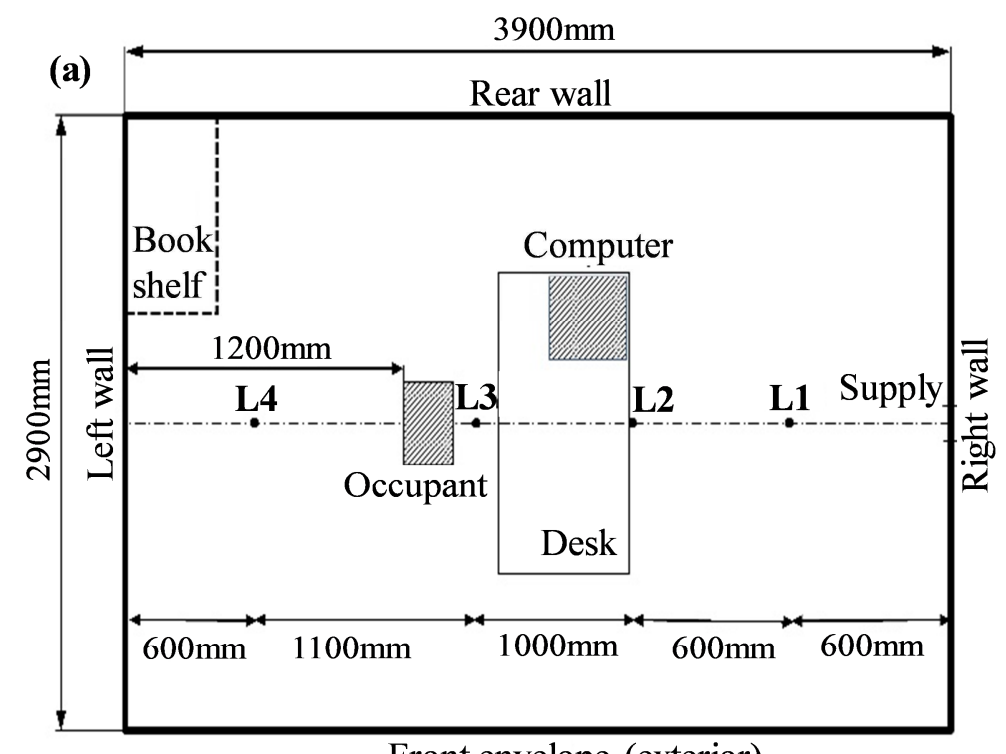

(b)

Front envelope (exterior)
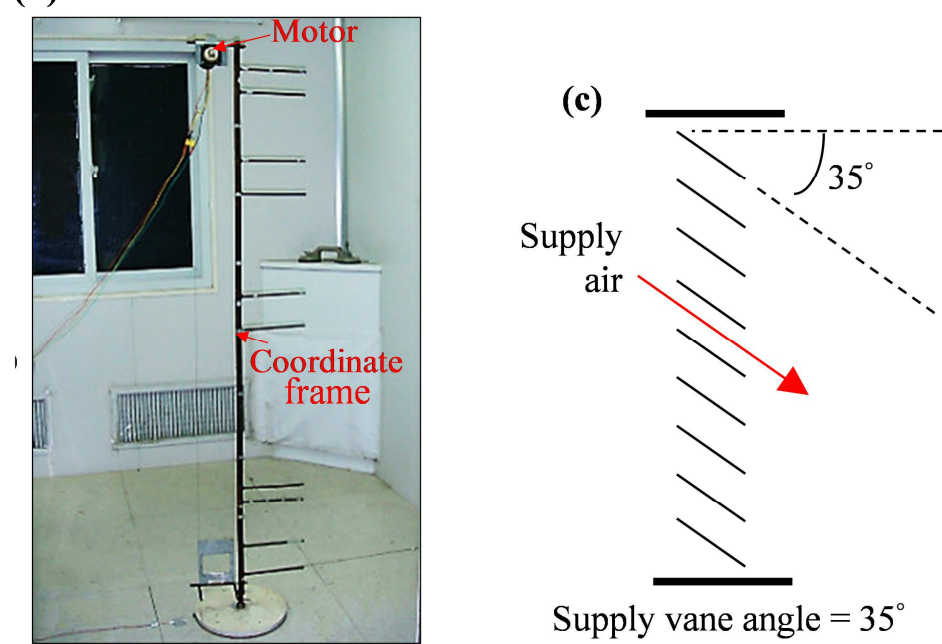

Note: L1 - L4 are the sampling lines.

Fig.1. Experiment setup: (a) Setup of test chamber; (b) automatic elevation system of one sampling line for adjusting positions of sensors; and (c) demonstration of definition of supply vane angle.

All measurements are conducted under steady state conditions. The supply airflow rate is set at 7.0 air changes per hour (ACH). The supply vane angle and supply air temperature are $0^{\circ}$ and $24^{\circ} \mathrm{C}$ respectively. The SWEMA omnidirectional anemometer systems are used to measure air velocity and temperature of four sampling lines (i.e. L1 - L4) at nine heights above floor: $0.3 \mathrm{~m}, 0.5 \mathrm{~m}, 0.7 \mathrm{~m}, 0.9 \mathrm{~m}, 1.1 \mathrm{~m}, 1.3 \mathrm{~m}, 1.5 \mathrm{~m}$, $1.7 \mathrm{~m}$ and $2.1 \mathrm{~m}$ (Figure 1(b)). For air velocity, the measurement range is $0.05-3 \mathrm{~m} / \mathrm{s}$, and the measurement error is $\pm 0.03 \mathrm{~m} / \mathrm{s}$ for $0.05-1.00 \mathrm{~m} / \mathrm{s}$ and $\pm 3 \%$ for $1.00-3.00$ $\mathrm{m} / \mathrm{s}$. It is noted that the measured air velocity refers to the air speed which only has 
the magnitude without information on the direction [27]. For air temperature, the measurement range is $10-34^{\circ} \mathrm{C}$, and the measurement error is $\pm 0.3^{\circ} \mathrm{C}$. To avoid the disturbance of laboratory staff on indoor airflow, the anemometers are elevated automatically using an elevation system with a motor from one height on the coordinate frame to another (Figure 1(b)). A Copper - Copper Nickel thermocouple system is used to measure wall surface temperatures. The measurement range for this system is $0-200^{\circ} \mathrm{C}$ and the measurement error is $\pm 0.5^{\circ} \mathrm{C}$. The $\mathrm{CO}_{2}$ concentration is measured by the TSI-IAQCAL system. The measuring range is $0 \mathrm{ppm}$ to $6000 \mathrm{ppm}$ and the measurement error is $\pm 3 \%$. During the experiments, the indoor relative humidity is monitored to be about $45 \%$. The information on the measurement tools is summarized in Table 1.

Table 1. Information on measurement tools.

\begin{tabular}{|l|l|l|}
\hline \multicolumn{1}{|c|}{$\begin{array}{c}\text { Measured } \\
\text { parameter }\end{array}$} & \multicolumn{1}{c|}{ Tool } & \multicolumn{1}{c|}{ Measurement error } \\
\hline Air temperature & $\begin{array}{l}\text { SWEMA omnidirectional } \\
\text { anemometer system }\end{array}$ & $\pm 0.3^{\circ} \mathrm{C}$ between $10-34^{\circ} \mathrm{C}$ \\
\hline Air velocity & $\begin{array}{l}\text { SWEMA omnidirectional } \\
\text { anemometer system }\end{array}$ & $\begin{array}{l} \pm 0.03 \mathrm{~m} / \mathrm{s} \text { between } 0.05-1.00 \\
\mathrm{~m} / \mathrm{s} ; \\
\pm 3 \% \text { between } 1.00-3.00 \mathrm{~m} / \mathrm{s}\end{array}$ \\
\hline $\begin{array}{l}\text { Wall surface } \\
\text { temperature }\end{array}$ & $\begin{array}{l}\text { Copper - Copper Nickel } \\
\text { thermocouple }\end{array}$ & $\pm 0.5^{\circ} \mathrm{C}$ between $0-200^{\circ} \mathrm{C}$ \\
\hline $\mathrm{CO}_{2}$ concentration & TSI-IAQCAL system & $\pm 3 \%$ between $0-6000 \mathrm{ppm}$ \\
\hline
\end{tabular}

\subsection{CFD simulations}

CFD simulations have been widely adopted to simulate indoor air flow, indoor air temperature, and contaminant dispersion, etc. [32-36]. Compared with experiments, CFD simulations cost less, and can provide more detailed information of flow fields. The experimental measurements can be used to validate the CFD simulations, and the experimentally validated CFD simulations can be reliably applied to conduct further parametric studies $[33,37]$.

The similar physical model as the experiments is used for the CFD simulations 
(Figure 2(a)). However, there are two differences between them. One is that a bookshelf is added in the CFD model to better realistically resemble a typical office environment. The other is that room air is exhausted by an outlet located in the lower level along the same wall as the supply diffuser, because this outlet layout can provide better thermal comfort and indoor air quality [23]. Airpak 3.0.16 [38] is employed to construct the physical model and generate mesh (Figure 2(b)). A commercial ANSYS Fluent code [39] is used to compute the air flow, air temperature and $\mathrm{CO}_{2}$ dispersion inside the office. Our previous studies showed that compared with the RNG $k$ - $\varepsilon$ model and SST $k-\omega$ model, the standard $k-\varepsilon$ model slightly better predicted the air velocities and temperatures of stratum ventilation [40]. It is noted that the advanced turbulence models (e.g. detached eddy simulation and large eddy simulation) may provide better predictions than the RANS models (e.g., the standard $k-\varepsilon$ model), but their computational cost is more expensive. Similar to studies [40, 41], for the reasonable accuracy and relative high computational efficiency, the standard $k-\varepsilon$ model is adopted by this study. A standard wall function is employed to model the turbulent flow in the near-wall region [39]. To ensure that the first near-wall grid point is located in the logarithmic region, the non-dimensional wall distance, $\mathrm{y}+$, should be at least 11.225 [39]. In this study, $\mathrm{y}+$ fluctuates in the range of 13 - 290. To predict the $\mathrm{CO}_{2}$ dispersion, a species transport model is used [39]. The discrete ordinates model is used to compute the radiation heat transfer among the surfaces. Buoyancy effect is considered by the Boussinesq model [39]. 
(a)

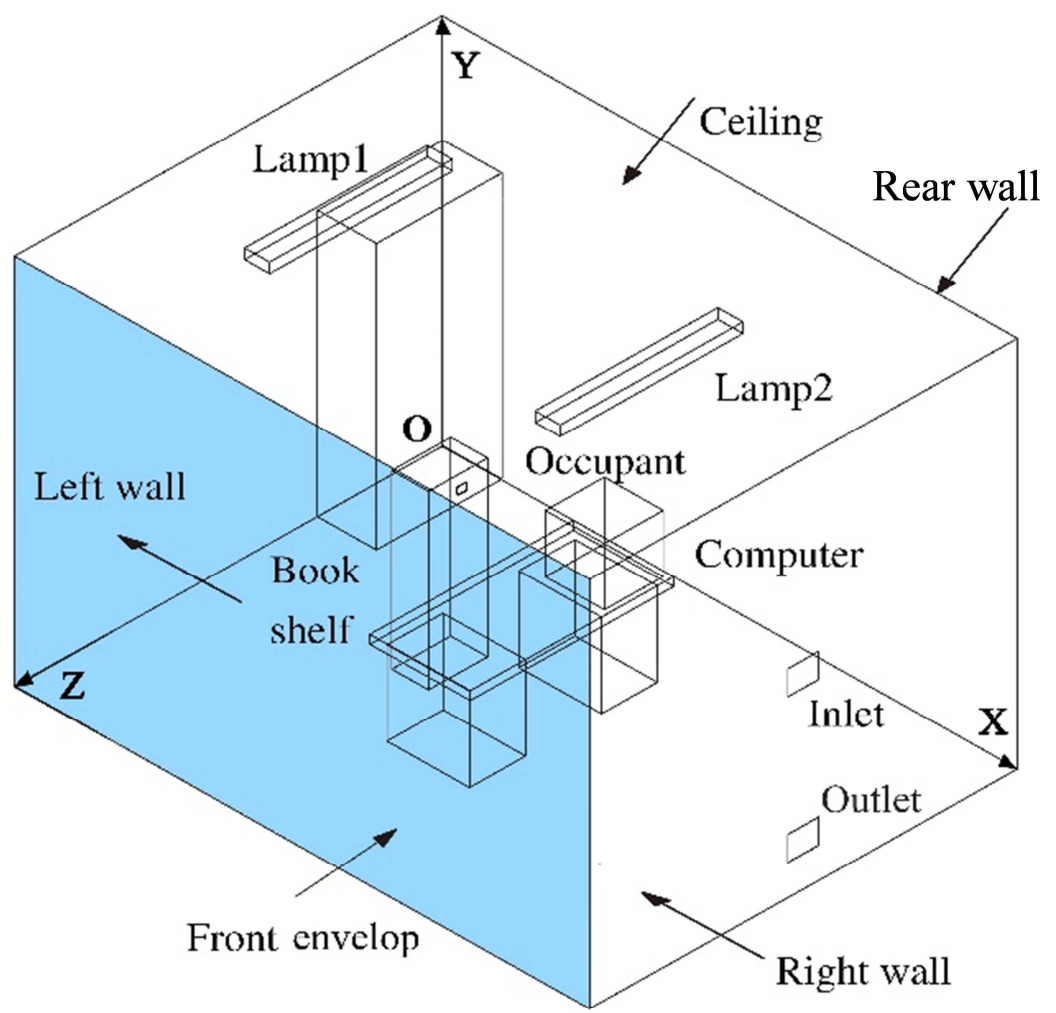

(b)

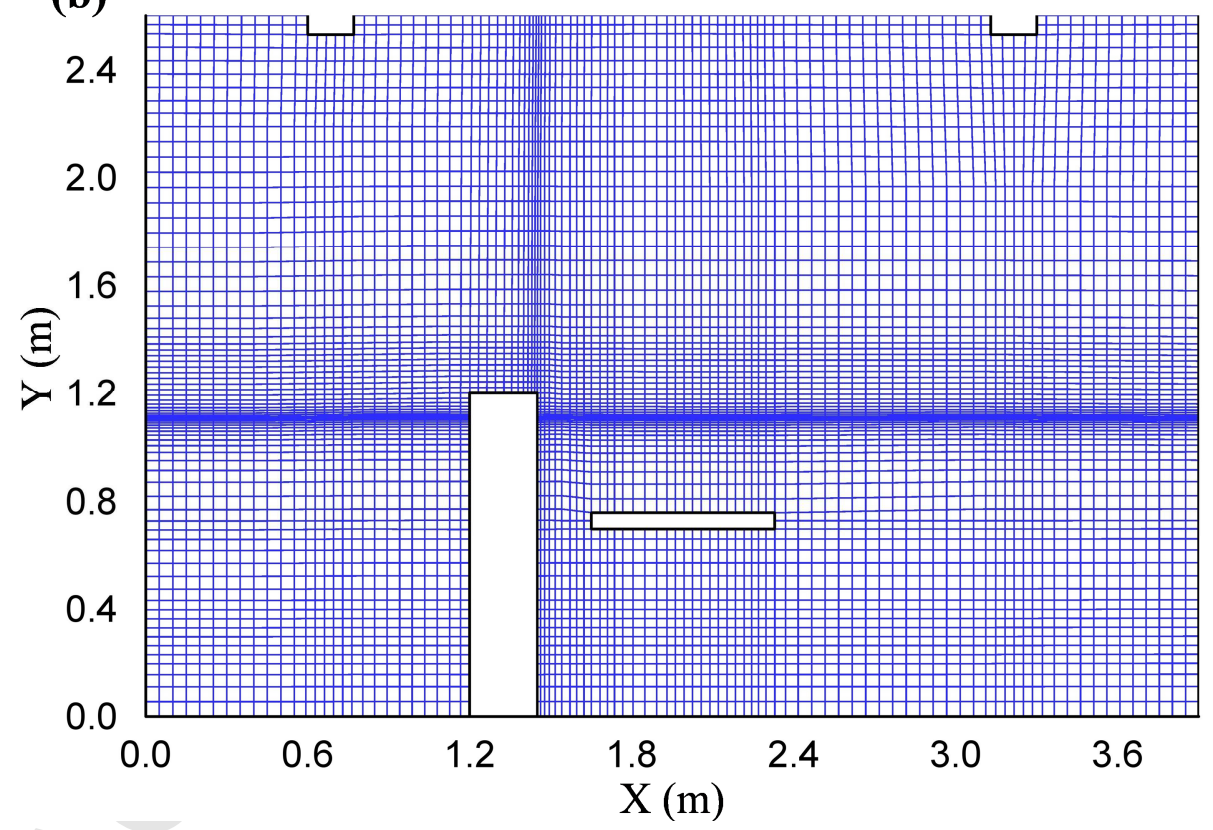

Fig.2. CFD model geometry: (a) Configuration of a typical stratum-ventilated office; and (b) mesh of computational domain $(\mathrm{Z}=1.45 \mathrm{~m})$.

The inlet is defined as an opening with uniform velocity, and the outlet is specified as the Neumann boundary condition. Based on the experiments, heat sources including the occupant, computer and ceiling lights are defined as a constant heat flux solid 
boundary condition. The front envelop is an exterior envelope, which is defined as the constant wall temperature to consider the effects of the outdoor weather condition [42, 43]. The other walls, floor and ceiling are assumed to be adiabatic. The occupant's mouth is set as velocity inlet boundary. The boundary conditions are summarized in Table 2.

Table 2. Boundary conditions of CFD simulations.

\begin{tabular}{|l|l|}
\hline Room air supply inlet & Uniform velocity inlet; $C_{\mathrm{s}}=400 \mathrm{ppm} ; \mathrm{TI}=10 \% ; \mathrm{D}=0.184 \mathrm{~m}$ \\
\hline Room air outlet & Neumann boundary condition \\
\hline Room front wall & Constant wall temperature, $10-17^{0} \mathrm{C}$ \\
\hline Other room walls & Adiabatic wall \\
\hline Occupant & Constant heat flux solid boundary, $45.2 \mathrm{~W} / \mathrm{m}^{2}$ \\
\hline Mouth & $\mathrm{L}=18 \mathrm{~L} / \mathrm{h} ; \mathrm{T}=37^{0} \mathrm{C} ; \mathrm{TI}=20 \%$ \\
\hline Computer & Constant heat flux solid boundary, $225 \mathrm{~W} / \mathrm{m}^{2}$ \\
\hline Ceiling lights & Constant heat flux solid boundary, $176.4 \mathrm{~W} / \mathrm{m}^{2}$ \\
\hline
\end{tabular}

For the grid-independent tests, this office is discretized using 310671 (Coarse), 613456 (Moderate) and 1193129 (Fine) hexahedral grids. The predicted air velocities and temperatures along the horizontal Sampling Line $(Y=1.3 \mathrm{~m}, \mathrm{Z}=1.45 \mathrm{~m}$ ) of the base case (i.e. Case 1 in Table 3 ) are compared for these three types of grids. Figure 3 shows that the predicted air velocities and temperatures using the moderate grid are close to those using the fine grid, whereas the air temperatures of the coarse grid show evident discrepancies from those of the fine grid. Thus, taking into consideration both the prediction accuracy and computational cost, the moderate grid is adopted. It is noted that the grids adjacent to the occupant, occupant's mouth, supply air inlet and air outlet are refined to capture the details of the flow variables (Figure 2(b)). The aspect ratio of the cell in the grid is managed to be less than 8 . The mesh quality is higher than 0.88 . 

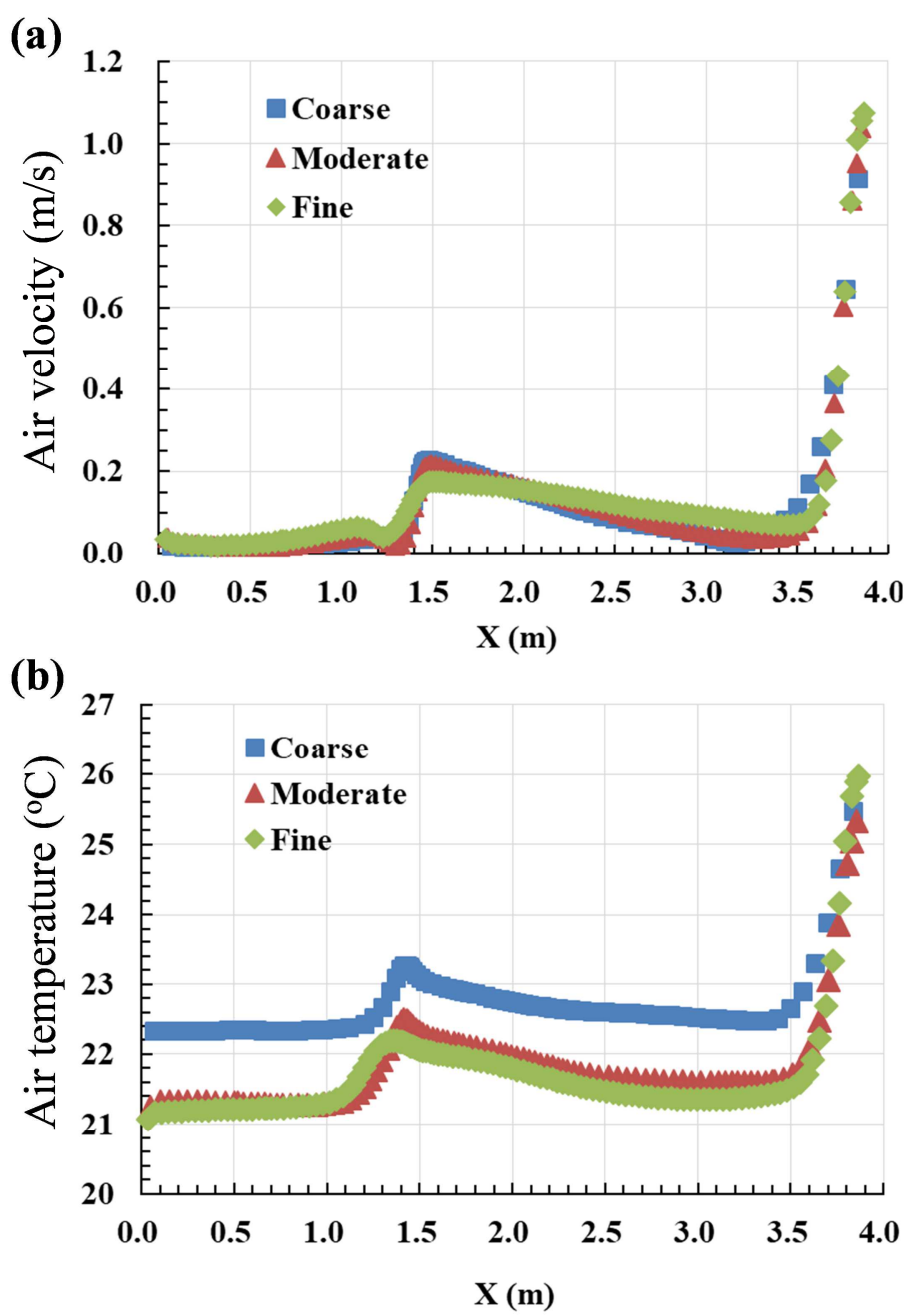

Fig.3. Comparisons of predictions using coarse, moderate and fine grids: (a) Air velocity; and (b) air temperature.

The turbulent Schmidt number can significantly affect the simulations of contaminant dispersion [44]. This number depends on the dominant flow structures, and is usually implemented as a constant [44]. In this study, different values (i.e. 0.1 - 0.9) of the turbulent Schmidt number have been tested, and 0.7 is selected for the turbulent Schmidt number because of the overall best agreements with the experimental data. The pressure-velocity coupling method is SIMPLE. The pressure interpolation is a staggered scheme called PRESTO. Both the convective and diffusion terms are discretized by second-order schemes to ensure the computational precision. Linear under-relaxation is used to ensure convergence of iteration. LMAA is determined by solving a transport scalar equation [45]. The converged criteria of the scaled residuals 
are as follows: $10^{-6}$ for energy, LMAA and $\mathrm{CO}_{2}$ concentration, and $10^{-4}$ for other variables. The air velocity, temperature and $\mathrm{CO}_{2}$ concentration at specific points are also monitored to achieve stable or steady quasi-periodic variations with small fluctuation amplitudes. Using the user-defined functions (UDFs) in ANSYS Fluent, $\Delta T$ and EUC are calculated based on the predicted field of air temperature, PMV is calculated based on the predicted fields of air temperature and velocity, and CRE is calculated based on the predicted field of $\mathrm{CO}_{2}$ concentration (Section 2.1).

\subsection{Studied cases}

The considered ranges of the operation parameters cover the values normally encountered in practice. The inside surface temperature of exterior envelope reflects the outdoor weather condition and ranges from $10^{\circ} \mathrm{C}$ to $17^{\circ} \mathrm{C}[42,43]$. The supply vane angle (Figure 1(c)), supply airflow rate and supply air temperature range from $0^{\circ}$ to $70^{\circ}, 0.02 \mathrm{~m}^{3} / \mathrm{s}$ to $0.04 \mathrm{~m}^{3} / \mathrm{s}, 22^{\circ} \mathrm{C}$ to $30^{\circ} \mathrm{C}$ respectively. All the operation parameters are normalized to be between 0 and 1 for sensitivity analysis (Equation 3) [46]. Normalization helps to remove anomalies caused by the different units and scales of the parameters [47]. Each operation parameter is allowed to be varied for five levels with equal intervals (i.e., 0, 0.25, 0.5, 0.75 and 1). One operation parameter is varied at one time while other operation parameters are maintained at the middle level (i.e., 0.5) [48-50]. As a result, 17 cases are determined (Table 3). For the purpose of comparison, Case 1 with all the operation parameters at the middle level is labeled as the base case [48-50].

$$
\bar{x}=\frac{x-x_{\min }}{x_{\max }-x_{\min }}
$$

Where $x$ and $\bar{x}$ are the original and normalized values respectively [46]; $x_{\max }$ and $x_{\min }$ are the maximal and minimal values of the original values respectively. 
Table 3. Studied cases: Normalized values of operation parameters.

\begin{tabular}{|c|c|c|c|c|}
\hline Case & $V A_{\mathrm{S}}$ & $V_{\mathrm{S}}$ & $T_{\mathrm{S}}$ & $T_{\mathrm{w}}$ \\
\hline 1 (Base) & 0.5 & 0.5 & 0.5 & 0.5 \\
\hline 2 & $\boldsymbol{0}$ & 0.5 & 0.5 & 0.5 \\
\hline 3 & $\mathbf{0 . 2 5}$ & 0.5 & 0.5 & 0.5 \\
\hline 4 & $\mathbf{0 . 7 5}$ & 0.5 & 0.5 & 0.5 \\
\hline 5 & $\boldsymbol{1}$ & 0.5 & 0.5 & 0.5 \\
\hline 6 & 0.5 & $\boldsymbol{0}$ & 0.5 & 0.5 \\
\hline 7 & 0.5 & $\boldsymbol{0 . 2 5}$ & 0.5 & 0.5 \\
\hline 8 & 0.5 & $\boldsymbol{0 . 7 5}$ & 0.5 & 0.5 \\
\hline 9 & 0.5 & $\boldsymbol{1}$ & 0.5 & 0.5 \\
\hline 10 & 0.5 & 0.5 & $\boldsymbol{0}$ & 0.5 \\
\hline 11 & 0.5 & 0.5 & $\boldsymbol{0 . 2 5}$ & 0.5 \\
\hline 12 & 0.5 & 0.5 & $\boldsymbol{0 . 7 5}$ & 0.5 \\
\hline 13 & 0.5 & 0.5 & $\boldsymbol{1}$ & 0.5 \\
\hline 14 & 0.5 & 0.5 & 0.5 & $\boldsymbol{0}$ \\
\hline 15 & 0.5 & 0.5 & 0.5 & $\boldsymbol{0 . 2 5}$ \\
\hline 16 & 0.5 & 0.5 & 0.5 & $\boldsymbol{0 . 7 5}$ \\
\hline 17 & 0.5 & 0.5 & 0.5 & $\boldsymbol{1}$ \\
\hline
\end{tabular}

Note: $V A_{s}$ is the supply vane angle from $0^{\circ}$ to $70^{\circ} ; V_{s}$ is the supply airflow rate from $0.02 \mathrm{~m}^{3} / \mathrm{s}$ to $0.04 \mathrm{~m}^{3} / \mathrm{s} ; T_{s}$ is the supply air temperature from $22{ }^{\circ} \mathrm{C}$ to $30{ }^{\circ} \mathrm{C} ; \mathrm{T}_{w}$ is the inside surface temperature of exterior envelope from $10^{\circ} \mathrm{C}$ to $17^{\circ} \mathrm{C}$.

\section{Results}

\subsection{Validation of CFD simulations}

With the same setup as the experiment, the predicted air temperatures, air velocities and $\mathrm{CO}_{2}$ concentrations by $\mathrm{CFD}$ simulations are compared with the measurements. As shown in Figure 4, the predictions generally show the similar variation patterns as the measurements. Both the simulated air temperatures and $\mathrm{CO}_{2}$ concentrations agree with the measurements well. But, the slightly larger velocity discrepancies are produced, especially for the measuring points above the height of $1.0 \mathrm{~m}$ for Sampling 
Lines 1 - 4. On the one hand, it is because these measuring points are within the supply air jet path (Figure 1(a)) and the simplified inlet model causes some of the discrepancies. Furthermore, the limitations of the Reynolds Averaged Navier-Strokes (RANS) turbulence models (e.g. the standard $k-\varepsilon$ model used in this study) in predicting complex flows involving swirls, vortices, locally transitional flows, etc. occurring in room ventilation can also cause some discrepancies [37, 51]. On the other hand, the omnidirectional thermal anemometers used in this study are difficult to accurately measure low air velocities [52]. The average absolute differences of the air temperature, air velocity and $\mathrm{CO}_{2}$ concentration between the CFD simulations and the measurements are $0.37^{\circ} \mathrm{C}, 0.09 \mathrm{~m} / \mathrm{s}$ and $13 \mathrm{ppm}$ respectively. The Pearson coefficients of the air velocity, air temperature and $\mathrm{CO}_{2}$ concentration between the predictions and measurements are $0.74,0.85$ and 0.70 respectively. The overall good agreement between the predictions and measurements indicates that the CFD simulations are reliable to simulate the air flow, air temperature and contaminant dispersion under stratum ventilation for heating applications. 
(a) Air temperature
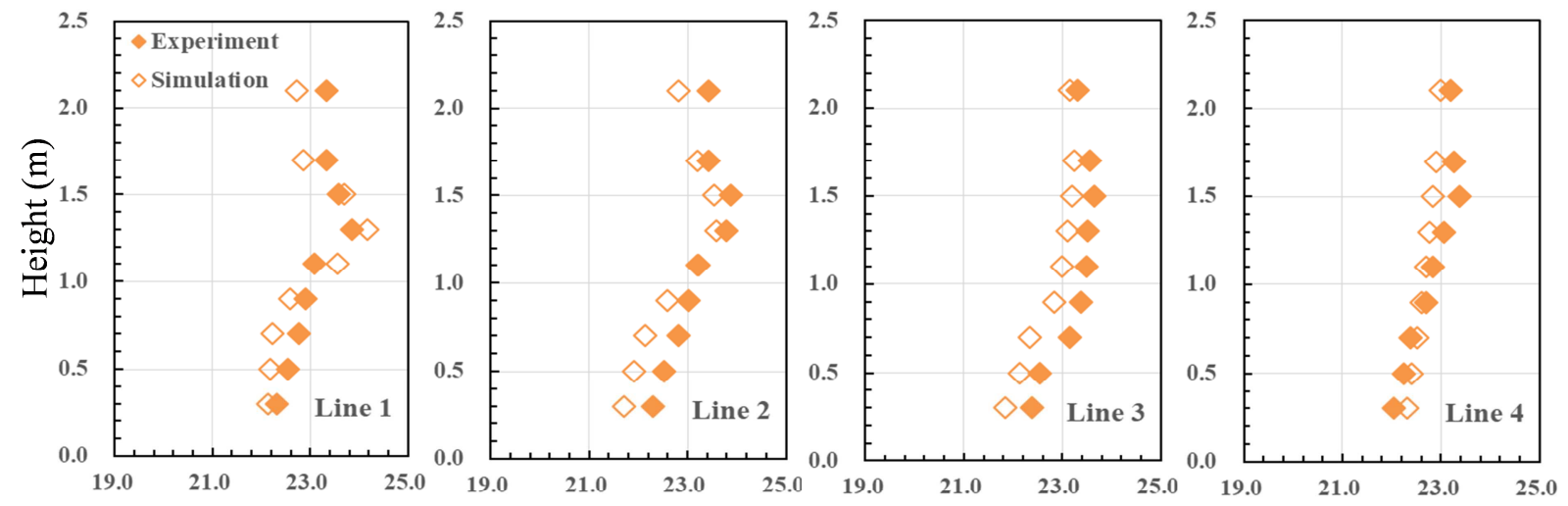

(b) Air velocity
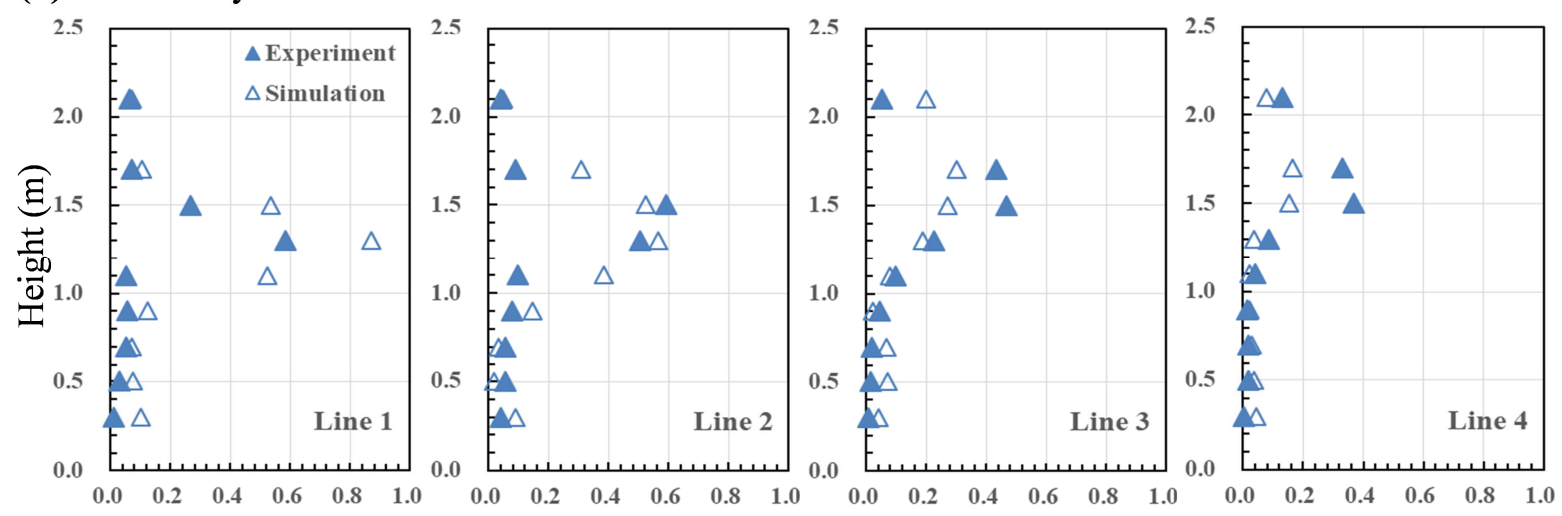

(c) $\mathrm{CO}_{2}$ concentration

Velocity $(\mathrm{m} / \mathrm{s})$
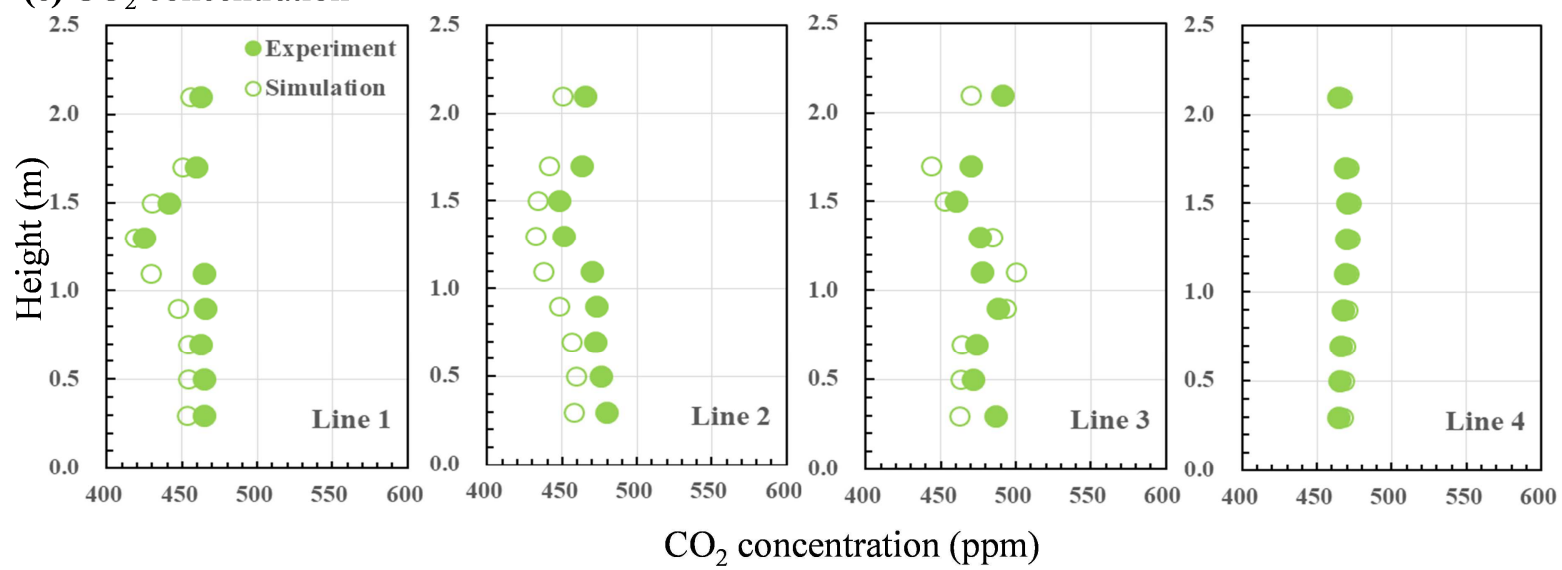

Fig.4. Comparisons between CFD simulations and experiments: (a) Air temperature;

(b) air velocity; and (c) $\mathrm{CO}_{2}$ concentration.

\subsection{Individual effects of operation parameters on ventilation performances}

A dimensionless influence coefficient is defined in Equation 4 to quantify the individual effect of each operation parameter on the ventilation performances $[49,53]$.

A larger absolute value of the influence coefficient indicates a more significant effect. 


$$
I C=\frac{\Delta O P}{O P_{b c}} / \frac{\Delta I P}{I P_{b c}}
$$

where $I C$ is the influence coefficient; $\triangle I P$ and $\triangle O P$ are the changes in the input and output respectively; $I P_{b c}$ and $O P_{b c}$ are the input and output of the base case respectively.

\subsubsection{Ventilation performances of base case}

Figure 5 shows the airflow pattern and $\mathrm{CO}_{2}$ concentration field of the base case. It can be seen from Figure 5(a) that, with the supply vane angle of $35^{\circ}$, the downward initial momentum suppresses the impacts of the thermal buoyancy. The convective flow around the human body is disrupted by the invading supply jet. As a result, the supply air can reach the upper body to efficiently provide quality air and thermal comfort with an LMAA of $845 \mathrm{~s}$ and a PMV of 0.01. $\Delta T$ is moderate at $1.84^{\circ} \mathrm{C}$. The occupied zone is effectively warmed, with the air temperature in the occupied zone higher than the exit air temperature. Thus, a high energy efficiency is achieved, with an EUC of 1.20. Since the air is directly supplied to the occupied zone, $\mathrm{CO}_{2}$ in the breathing zone can be efficiently removed, with a CRE of 1.06 (Figure 5(b)). Since the exhaled jet velocity is low, the exhaled $\mathrm{CO}_{2}$ flows upwards immediately with the help of the thermal buoyancy [11]. Overall, the ventilation performances of the base case are satisfactory. 

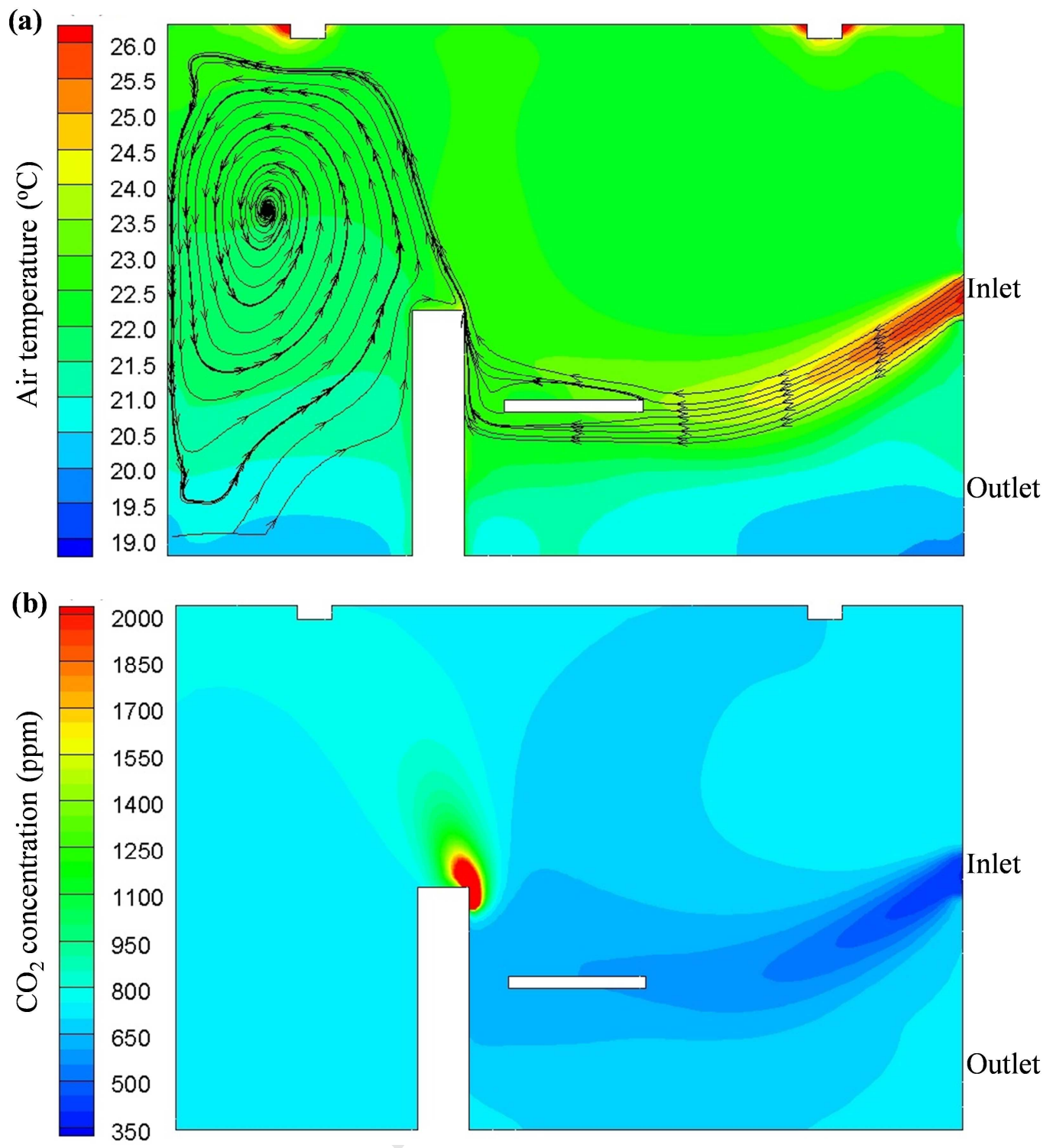

Fig.5. Room central vertical section fields for base case: (a) Air temperature and (b) $\mathrm{CO}_{2}$ concentration.

\subsubsection{Individual effects on indoor air quality}

The influence coefficients of the supply vane angle, supply airflow rate, supply air temperature and inside surface temperature of exterior envelope on LMAA are 0.45, $-0.67,-0.12$ and -0.05 respectively (Table 4). Thus, LMAA is most sensitive to the supply airflow rate, followed by the supply vane angle, supply air temperature and then inside surface temperature of exterior envelope. In other words, the supply airflow rate is the most important operation parameter to LMAA, followed by the supply vane angle, supply air temperature and then inside surface temperature of 
exterior envelope. The negative influence coefficients of the supply airflow rate, supply air temperature and inside surface temperature of exterior envelope indicate that increasing these three operation parameters would lower LMAA to improve indoor air quality.

Table 4. Influence coefficients of operation parameters on ventilation performances.

\begin{tabular}{|c|c|c|c|c|}
\hline & $V A_{\mathrm{s}}$ & $V_{\mathrm{s}}$ & $T_{\mathrm{s}}$ & $T_{\mathrm{w}}$ \\
\hline LMAA & 0.45 & $-0.67 *$ & -0.12 & -0.05 \\
\hline CRE & $-0.54^{*}$ & -0.20 & 0.07 & -0.08 \\
\hline PMV & -16.85 & 12.62 & $115.38^{*}$ & 33.23 \\
\hline$\Delta T$ & -0.93 & -0.35 & $1.07 *$ & 0.50 \\
\hline EUC & $-0.39 *$ & 0.09 & -0.06 & 0.15 \\
\hline
\end{tabular}

Note: * labels the most important operation parameter for each ventilation performance.

Figure 6 shows the variations of LMAA with the four operation parameters. The variations of LMAA with its most important operation parameter are explained as follows. When the normalized supply airflow rate increases from 0 to 1 , LMAA decreases from $1414 \mathrm{~s}$ to $650 \mathrm{~s}$. This is because that the larger the supply airflow rate, the larger the supply air velocity, thereby the larger the downward initial momentum. The increased downward initial momentum weakens the impacts of the thermal buoyancy. As a result, the supply air can reach the breathing zone more quickly and the air in the breathing zone is younger. 


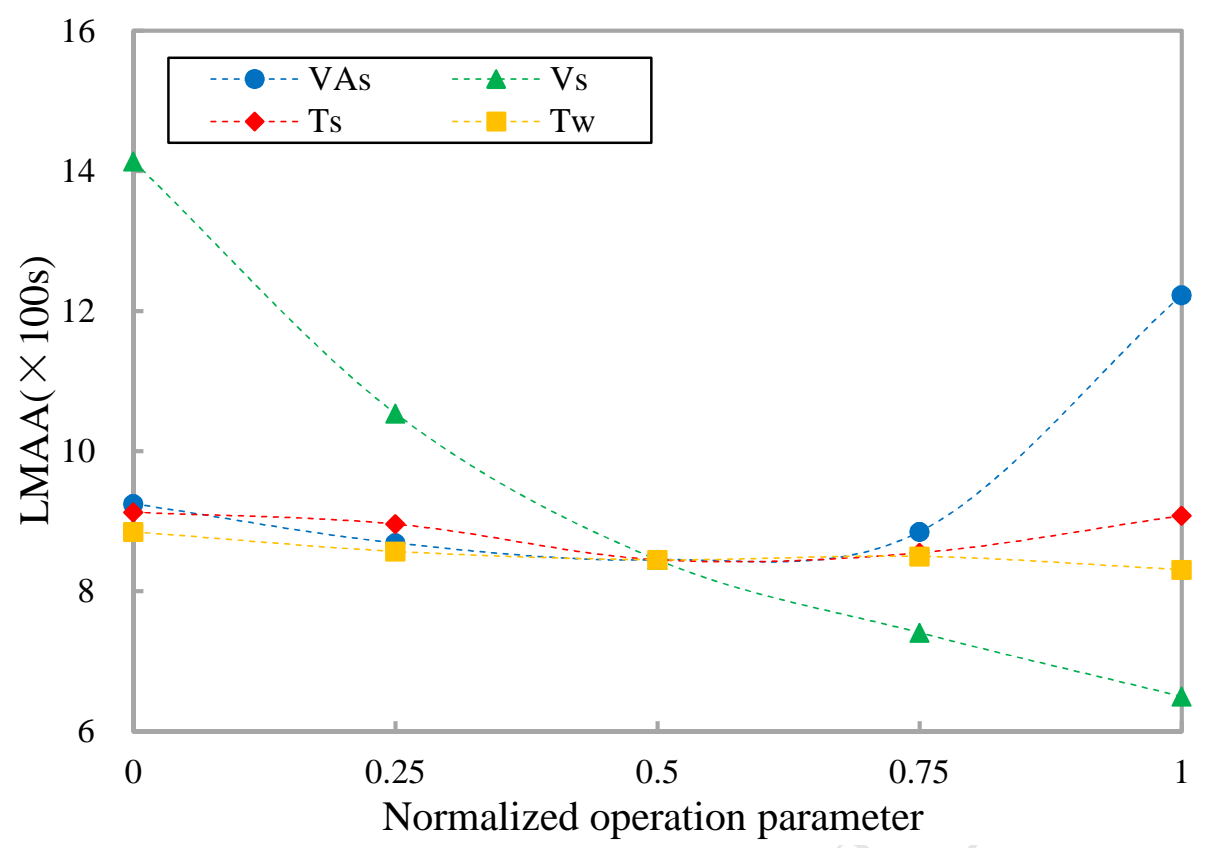

Fig.6. Variations of local mean age of air (LMAA) with operation parameters.

Regarding CRE, the supply vane angle is the most important operation parameter, followed by the supply airflow rate, inside surface temperature of exterior envelope and then supply air temperature (see the influence coefficients in Table 4). Figure 7 shows the variations of CRE with the four operation parameters. The variations of CRE with its most important operation parameter are explained as follows. With the normalized supply vane angle increasing from 0 to 0.5 , CRE increases from 0.96 to 1.06 (Figure 7). When the normalized supply vane angle is zero, the warm air is horizontally supplied and flows into the upper zone due to the thermal buoyancy. With increasing the normalized supply vane angle to 0.5 , the warm air is supplied with a downward initial momentum. The downward initial momentum suppresses the upward thermal buoyancy to some extent. As a result, the supply air reaches the upper body to dilute and take away the exhaled $\mathrm{CO}_{2}$, leading to an increase in CRE. When the normalized supply vane angle increases to $1, \mathrm{CRE}$ decreases to 0.63 . With the over-downward supply air, the short-circuiting is caused and part of supply air is directly exhausted without entering the occupied zone (Figure 8). Thus, CRE decreases dramatically. 


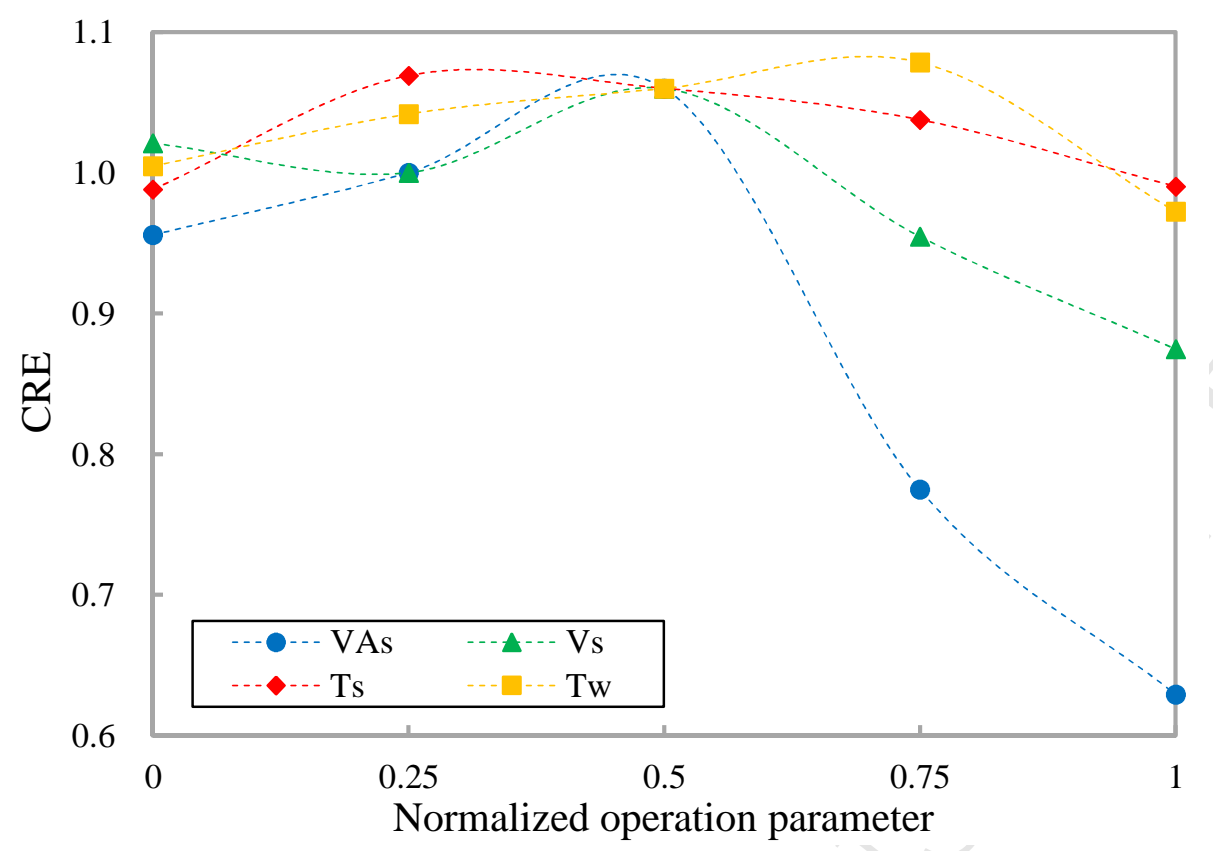

Fig.7. Variations of $\mathrm{CO}_{2}$ removal efficiency (CRE) with operation parameters.

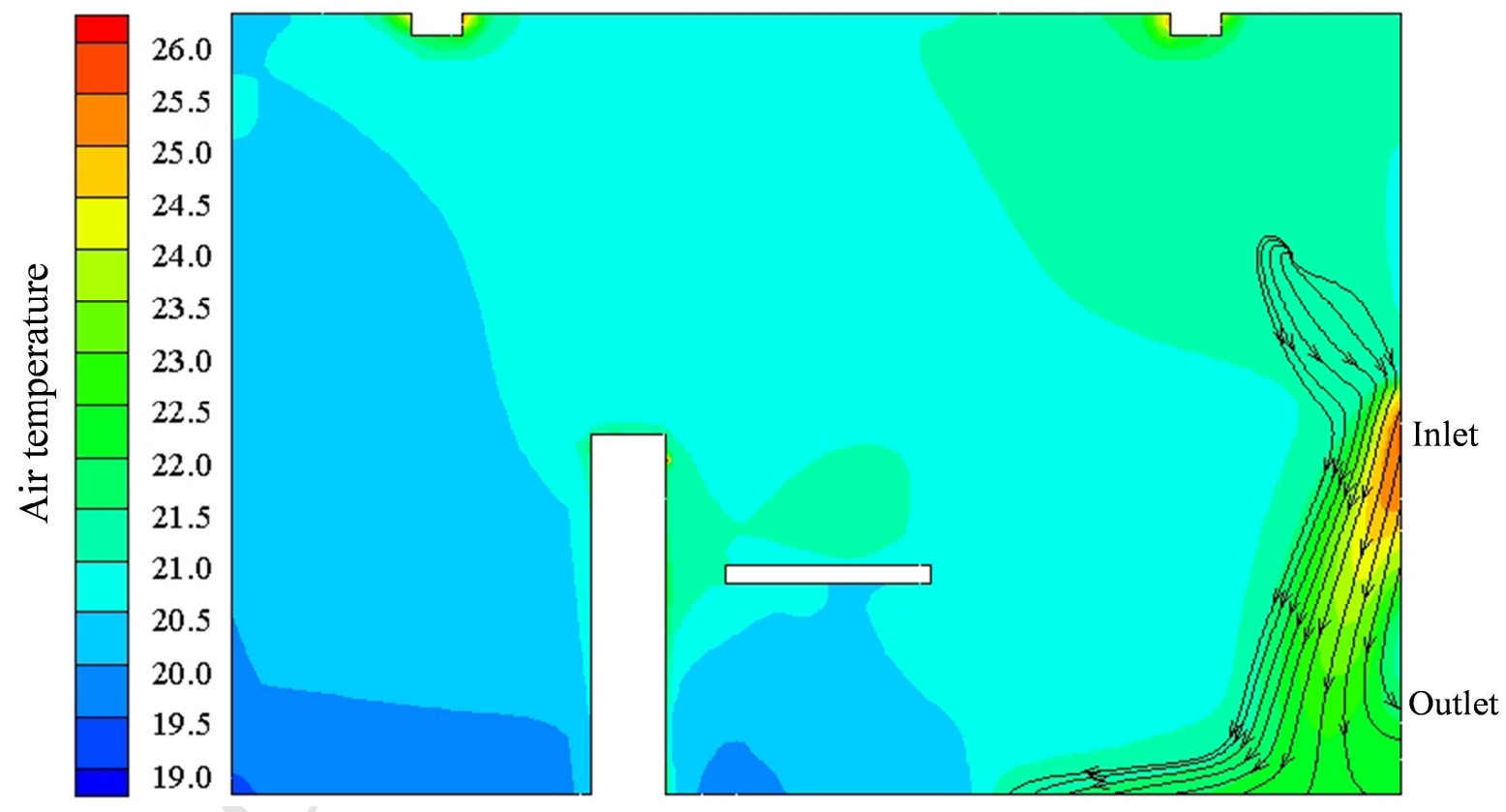

Fig.8. Airflow patterns with normalized supply vane angles of 1.

\subsubsection{Individual effects of operation parameters on thermal comfort}

From Table 4, it can be seen that PMV is most sensitive to the supply air temperature, followed by the inside surface temperature of exterior envelope, supply vane angle and then supply airflow rate, with the corresponding influence coefficients of 115.38 , 
33.23, -16.85 and 12.62 respectively. Compared with other ventilation performance indices, the influence coefficients of PMV are larger. This is because that PMV of the base case is close to zero (i.e., thermal neutrality) (Equation 4). Figure 9 shows the variations of PMV with the four operation parameters. The variations of PMV with its most important operation parameter are explained as follows. When the normalized supply air temperature increases from 0 to $1, \mathrm{PMV}$ increases from -0.86 to 0.36 . Particularly, when the normalized supply air temperature increases from 0.25 to 0.5 , the increase of PMV is faster from -0.74 to 0.01 . With the normalized supply air temperature between 0.25 and 0.5 , the thermal buoyancy is moderate, so the supply air can directly enter the occupied zone to warm the body. However, when the supply air temperature is over-low or over-high, the thermal buoyancy is over-small or over-large, so the supply air either strikes directly the floor or flows upwards directly to the upper zone.

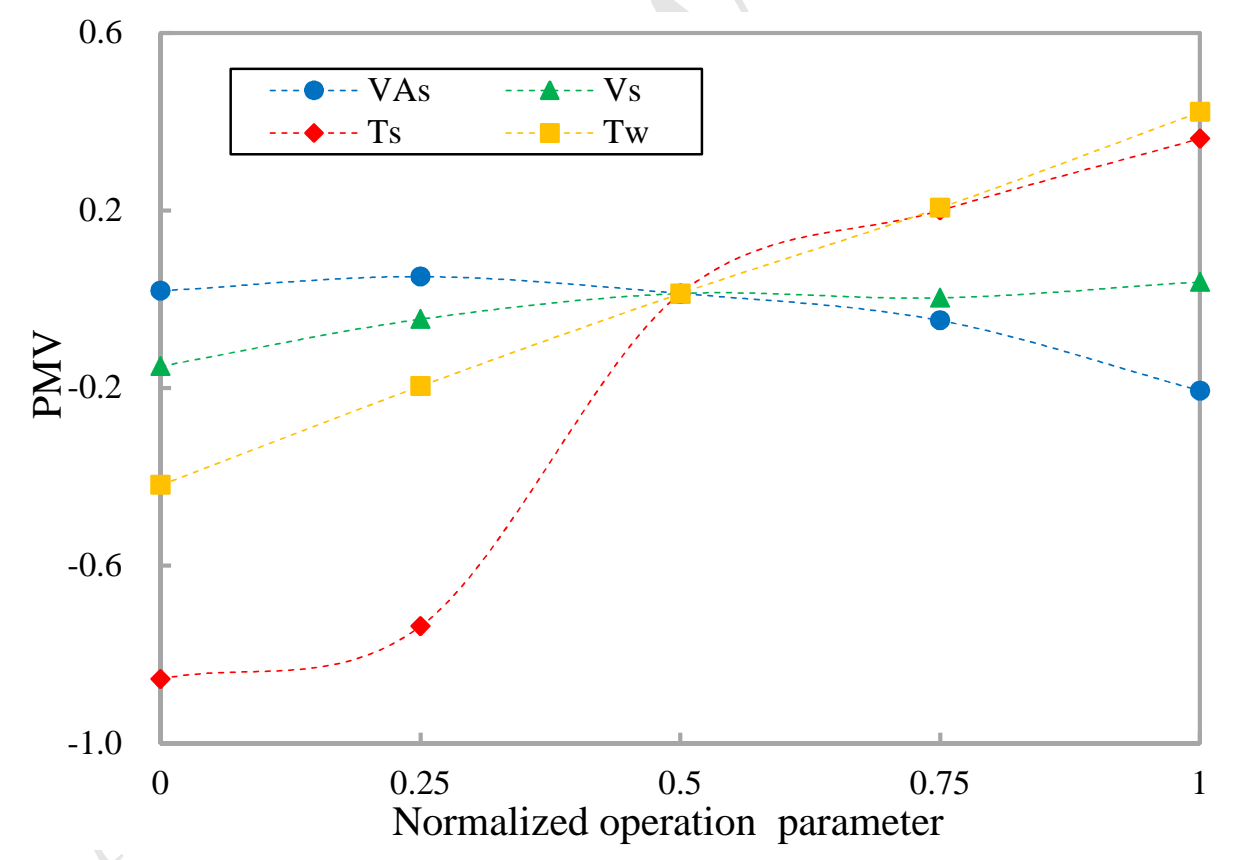

Fig.9. Variations of Predicted Mean Vote (PMV) with operation parameters.

The influence coefficients in Table 4 show that $\Delta T$ is most sensitive to the supply air temperature, followed by the supply vane angle, inside surface temperature of exterior envelope and then supply airflow rate. The variations of $\Delta T$ with the four operation 
parameters can be seen from Figure 10. The variations of $\Delta T$ with its most important operation parameter are explained as follows. When the normalized supply air temperature increases from 0 to $1, \Delta T$ increases from $0.67^{\circ} \mathrm{C}$ to $2.75^{\circ} \mathrm{C}$. The increased supply air temperature with the increased thermal buoyancy more effectively elevates the air temperature at the height of $1.1 \mathrm{~m}$ than that at the height of $0.1 \mathrm{~m}$, which enlarges the air temperature difference between the two heights. It is noted that although Figure 10 shows that the normalized supply vane angle of 1 results in a small $\Delta T$ of $0.70^{\circ} \mathrm{C}$, it is inadvisable to adopt the largest supply vane angle for the small $\Delta T$. This is because that with the largest supply vane angle, part of the supply air is directly exhausted due to the short-circuiting (Figure 8).

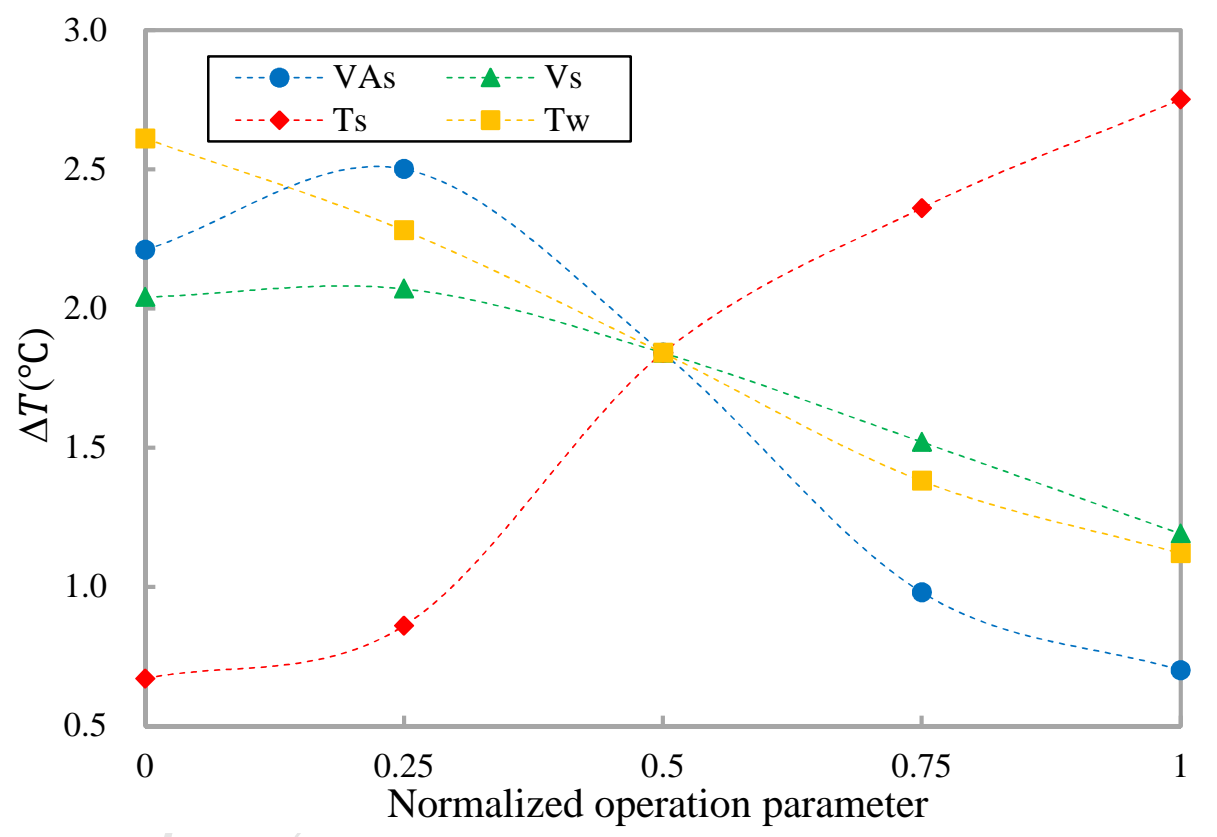

Fig.10. Variations of vertical air temperature difference between head and ankle levels $(\Delta T)$ with operation parameters.

\subsubsection{Individual effects of operation parameters on energy efficiency}

It can be seen from the influence coefficients in Table 4 that EUC is most sensitive to the supply vane angle, followed by the inside surface temperature of exterior envelope, supply airflow rate and then supply air temperature. When the normalized supply vane angle varies between 0 and 0.75 , the variation of EUC is mild from 1.12 to 1.20. 
When the normalized supply vane angle continually increases to 1, EUC decreases substantially to 0.74 . This is caused by the airflow short-circuiting (Figure 8). When the normalized inside surface temperature of exterior envelope, normalized supply airflow rate and normalized supply air temperature increase from 0 to 1, EUC varies from 1.16 to 1.38 , from 1.11 to 1.25 , from 1.15 to 1.20 respectively (Figure 11 ).

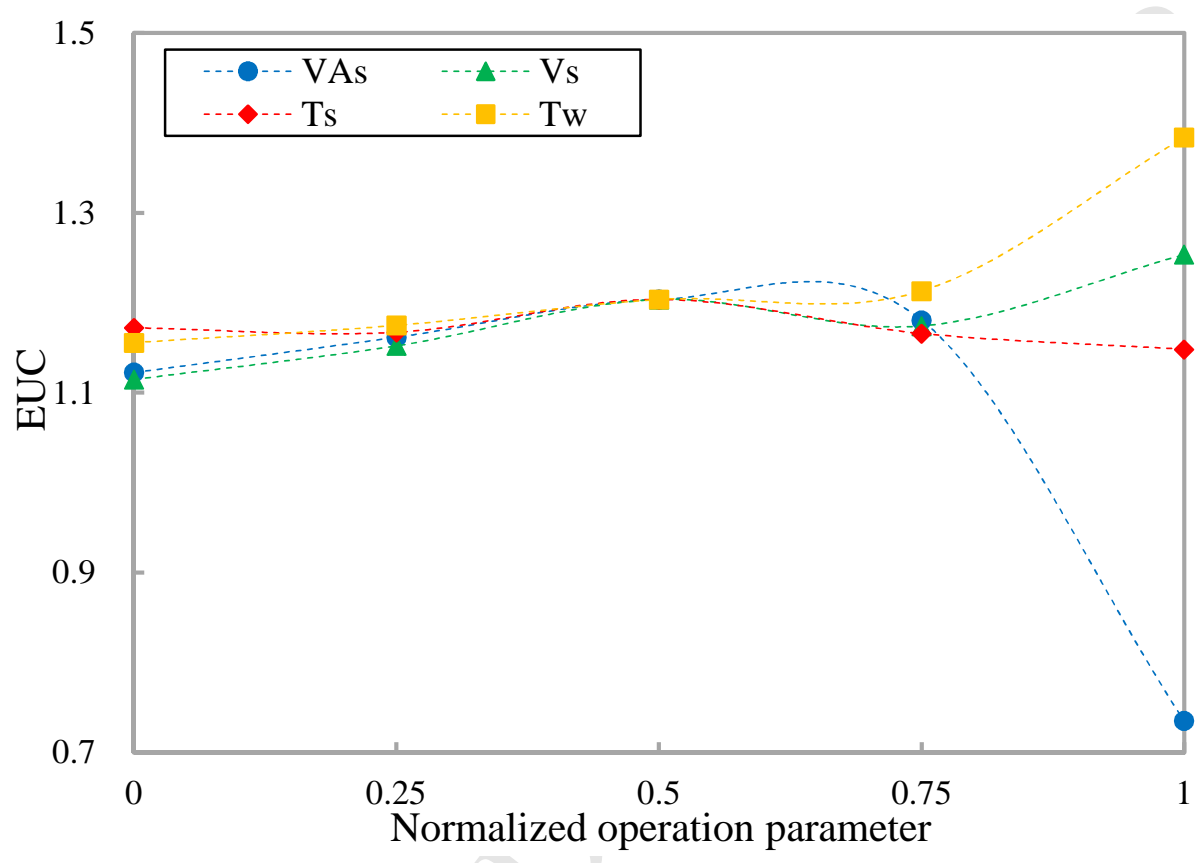

Fig.11. Variations of energy utilization coefficient (EUC) with operation parameters.

\subsection{Combined effects of operation parameters on ventilation performances}

In practice, the operation parameters could vary simultaneously. The combined effects of the operation parameters on ventilation performances can be evaluated by the method of room sum square (RSS) [48]. The RSS method is developed based on the uncertainty propagation theory [54]. According to the RSS method, the variation of a specific ventilation performance caused by the combined effects of the operation parameters is the root sum square of the variations of the ventilation performance caused by the individual effect of each operation parameter (Equation 5).

$$
R S S=\sqrt{\sum\left(\frac{\partial O P}{\partial I P_{i}} \Delta I P_{i}\right)^{2}}
$$

where $R S S$ is the root sum square; $i$ indicates the $i^{\text {th }}$ input. 


\subsubsection{Combined effects of operation parameters on indoor air quality}

Figure 12 shows the variations of LMAA caused by the combined effects of the operation parameters. When only the combined effects of the supply vane angle, supply airflow rate and supply air temperature are considered, the normalized inside surface temperature of exterior envelope is set at 0.5 [48]. LMAA increases from 650 $\mathrm{s}$ to $1531 \mathrm{~s}$ with the normalized supply vane angle, normalized supply airflow rate and normalized supply air temperature increasing simultaneously from 0 to 1 . Compared with the base case (with an LMAA of 845 s), the combined effects of the three controllable operation parameters on LMAA reveal that stratum ventilation for heating applications needs to be properly operated for reducing LMAA (e.g., from $845 \mathrm{~s}$ to $650 \mathrm{~s}$ ). Otherwise, the improper operation could severely deteriorate LMAA (e.g., from 845 s to 1531 s). When the combined effects also take into consideration the inside surface temperature of exterior envelope, LMAA increases from $649 \mathrm{~s}$ to $1532 \mathrm{~s}$ with the four normalized operation parameters increasing simultaneously from 0 to 1 . The differences of LMAAs considering and without considering the inside surface temperature of exterior envelope are less than $1 \%$. This indicates that the outdoor weather condition does not significantly affect LMAA, which will be further discussed in Section 4.

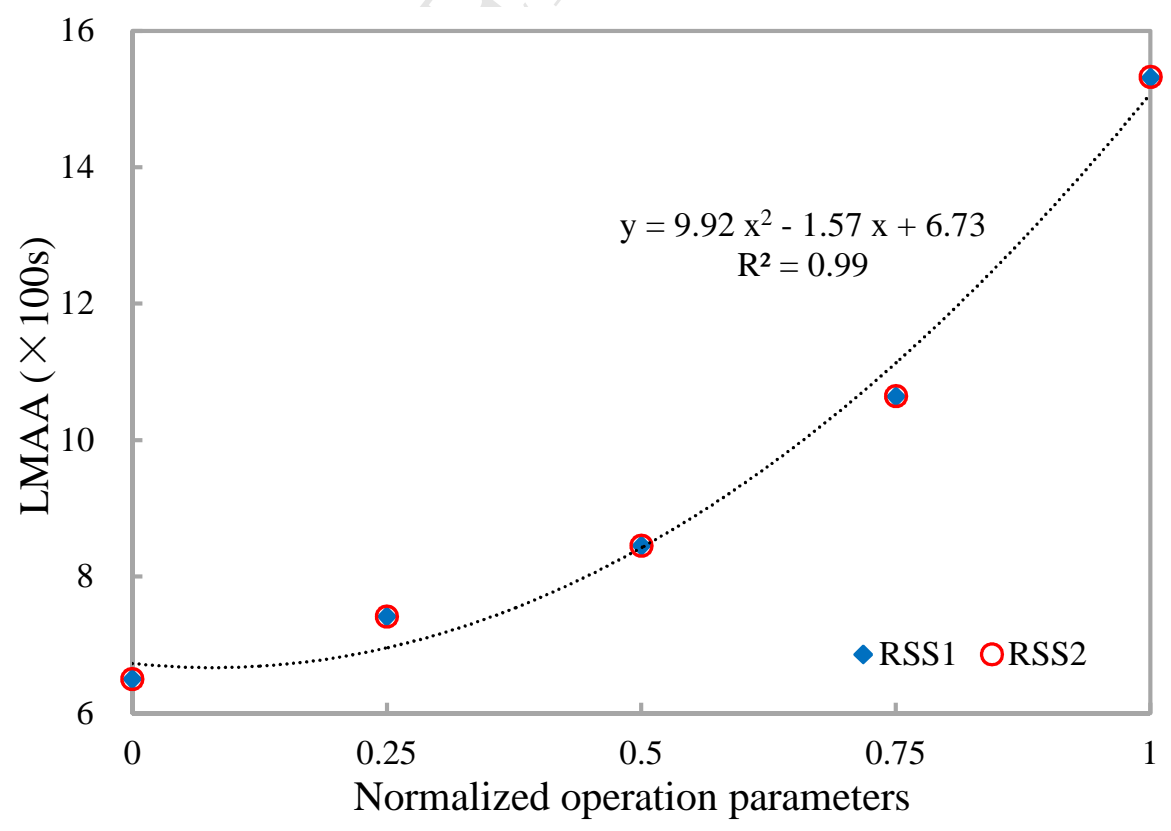

Note: RSS1 refers to combined effects of supply vane angle, supply airflow rate and supply air temperature; RSS2 refers to combined effects of supply vane angle, supply 
airflow rate, supply air temperature and inside surface temperature of exterior envelope.

Fig.12. Combined effects of operation parameters on local mean age of air (LMAA).

Figure 13 shows that when the inside surface temperature of exterior envelope is maintained the same as that of the base case, CRE varies from 0.59 to 1.07 caused by the combined effects of the other three operation parameters. The large variation of CRE indicates that it is imperative to appropriately control the three operation parameters to avoid the low CRE. Compared with the base case, although the improvement of CRE is marginal (i.e., from 1.06 to 1.07), the CRE deterioration due to the improper operation can be substantial (i.e., from 1.06 to 0.59 ). When the inside surface temperature of exterior envelope is considered, CRE varies from 0.58 to 1.08 caused by the combined effects of the four operation parameters. The differences of CREs with the invariable and variable inside surface temperatures of exterior envelope are less than $1.5 \%$. Thus, the effect of the outdoor weather condition on CRE is also negligible.

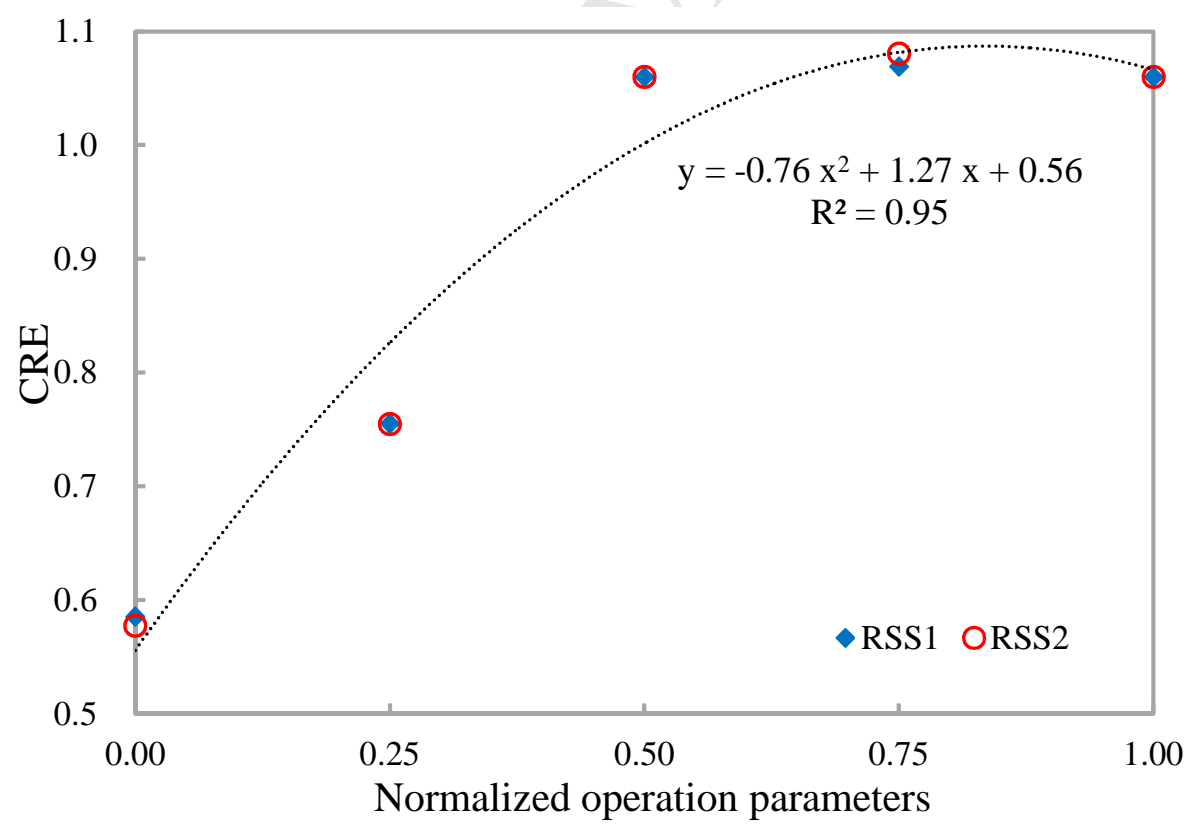

Fig.13. Combined effects of operation parameters on $\mathrm{CO}_{2}$ removal efficiency (CRE).

\subsubsection{Combined effects of operation parameters on thermal comfort}

When the inside surface temperature of exterior envelope is kept the same as that of the base case, compared with the base case, PMV can be decreased from 0.01 to -0.90 
and increased from 0.01 to 0.36 due to the combined effects of the three operation parameters (Figure 14). When the inside surface temperature of exterior envelope is variable, compared with the base case, PMV can be decreased by from 0.01 to -1 and increased from 0.01 to 0.55 due to the combined effects of the four operation parameters (Figure 14). The larger variation range of PMV with the variable inside surface temperature of exterior envelope indicates that the variation of the inside surface temperature of exterior envelope risks to cause the thermal environment from comfort to discomfort.

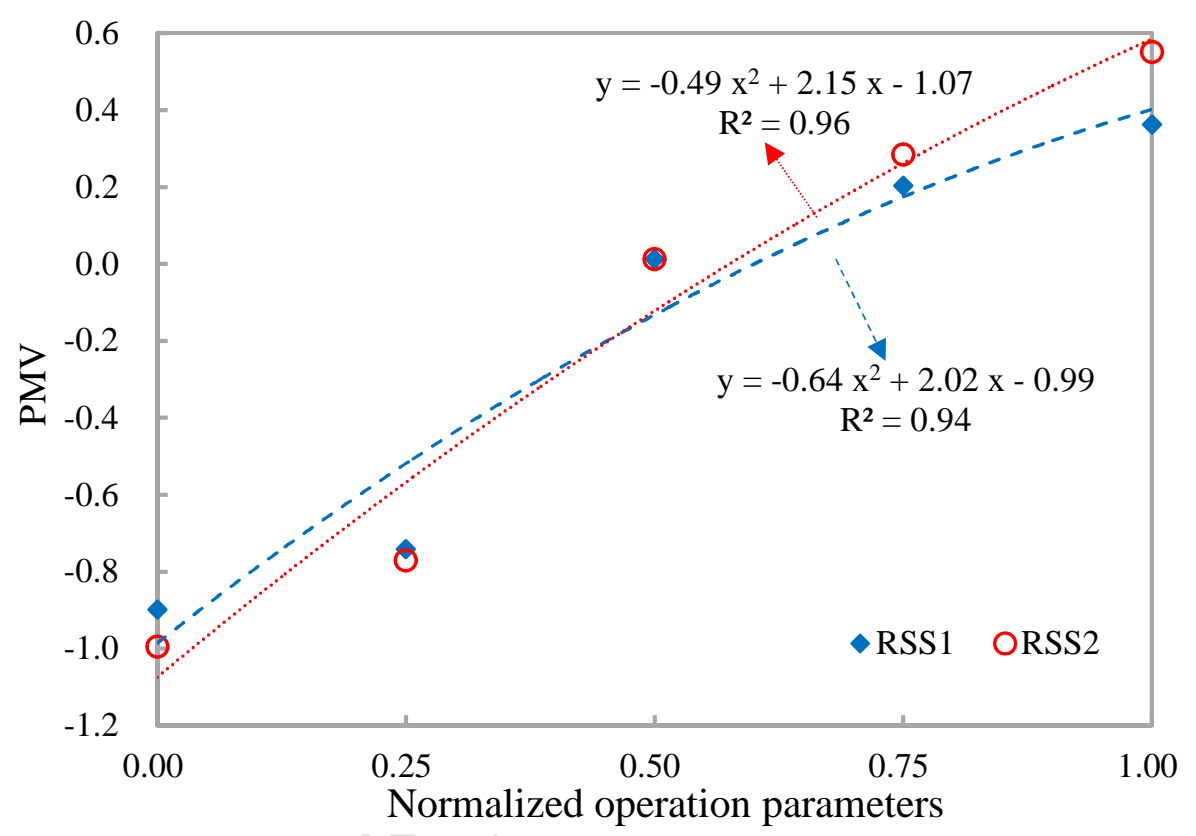

Fig.14. Combined effects of operation parameters on Predicted Mean Vote (PMV).

When the inside surface temperature of exterior envelope is the same as that of the base case, compared with the base case, $\Delta T$ can be decreased from $1.84^{\circ} \mathrm{C}$ to $0.08^{\circ} \mathrm{C}$ and increased from $1.84^{\circ} \mathrm{C}$ to $2.84^{\circ} \mathrm{C}$ due to the combined effects of the other three operation parameters (Figure 15). When the inside surface temperature of exterior envelope is variable, $\Delta T$ can be decreased from $1.84^{\circ} \mathrm{C}$ to $-0.06^{\circ} \mathrm{C}$ and increased from $1.84^{\circ} \mathrm{C}$ to $3.10^{\circ} \mathrm{C}$ due to the combined effects of the four operation parameters (Figure 15). Although the differences between $\Delta T$ with the variable inside surface temperature of exterior envelope and that with the fixed inside surface temperature of exterior envelope are small (less than $0.26^{\circ} \mathrm{C}$ ), the variation of the inside surface temperature of exterior envelope can result in local thermal discomfort with $\Delta T$ beyond the upper limit of $3^{\circ} \mathrm{C}$ stipulated by ASHRAE 55 [28]. This is mainly because 
the downdraft produced by the cold exterior envelop reduces the air temperature at the ankle level [43].

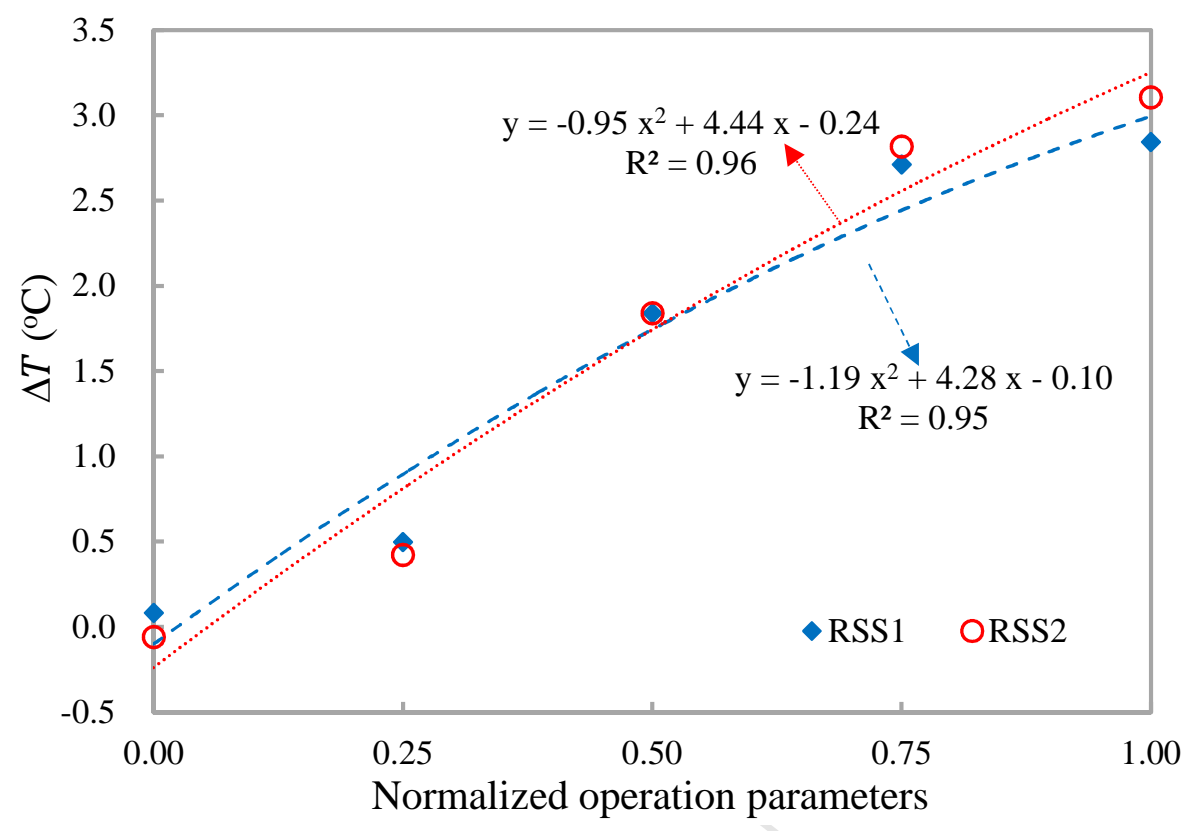

Fig.15. Combined effects of operation parameters on vertical air temperature difference between head and ankle levels $(\Delta T)$.

\subsubsection{Combined effects of operation parameters on energy efficiency}

When the inside surface temperature of exterior envelope is kept the same as that of the base case, compared with the base case, EUC can be decreased from 1.20 to 0.72 and increased from 1.20 to 1.25 due to combined effects of the other three operation parameters (Figure 16). When the inside surface temperature of exterior envelope is variable and the normalized operation parameters are not greater than 0.75, EUCs resulting from the combined effects with the variable and fixed inside surface temperatures of exterior envelope are similar, with differences less than $1 \%$. However, when the normalized operation parameters increase to 1, EUC with the variable inside surface temperature of exterior envelope increases from 1.25 to 1.39 as compared with the fixed inside surface temperature of exterior envelope. 


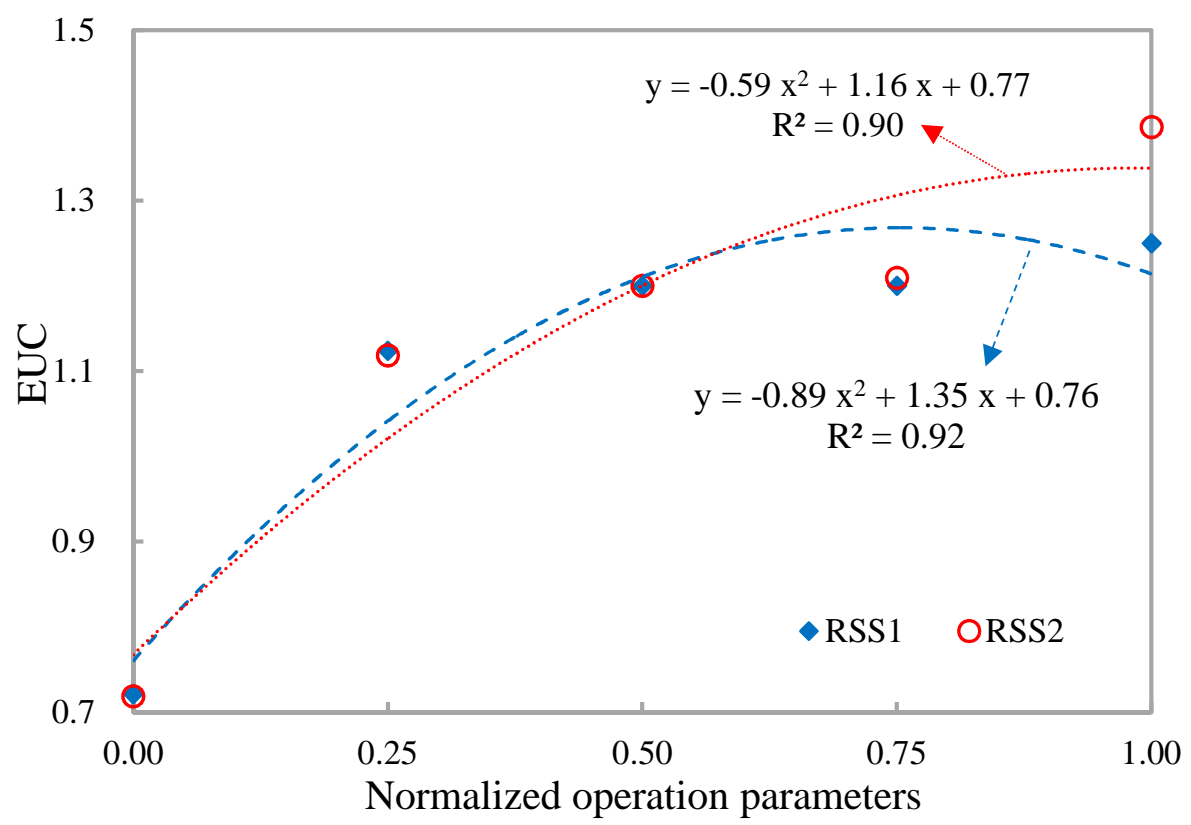

Fig.16. Combined effects of operation parameters on energy utilization coefficient (EUC).

\section{Discussion}

The analysis of individual effects of the operation parameters on the ventilation performances reveals that the most important operation parameter of each ventilation performance is the controllable one rather than the uncontrollable outdoor weather condition. The supply vane angle is most important to CRE and EUC, the supply airflow rate is most important to LMAA, and the supply air temperature is most important to thermal comfort (i.e., PMV and $\Delta T$ ) (Section 3.2). While the cooling applications of stratum ventilation fix the supply vane angle at $0^{\circ}[2]$, the supply vane angle is preferred at $35^{\circ}$ for a large CRE and a large EUC when stratum ventilation is used for heating (Figures 7 and 11). This confirms that the operation of stratum ventilation for heating applications is distinct from that for cooling applications.

The variations of the ventilation performances caused by the corresponding most important operation parameters and the combined effects of the four operation parameters are compared. For example, the supply airflow rate can cause LMAA to vary from $650 \mathrm{~s}$ to $1414 \mathrm{~s}$ (Figure 6), while the combined effects of the four operation 
parameters can cause LMAA to vary from $649 \mathrm{~s}$ to $1531 \mathrm{~s}$ (Figure 12). The variations of LMAA caused by the supply airflow rate alone overlap $86.5 \%$ of the variations of LMAA caused by the combined effects of the four operation parameters. In other words, the supply airflow rate can explain $86.5 \%$ variations of LMAA. Thus, in order to improve LMAA, properly determining the supply airflow rate is adequate in practice if a comprehensive and convenient overall optimization of all operation parameters is unavailable. Similarly, $85.6 \%$ variations of CRE can be explained by the supply vane angle (Figures 7 and 13); 78.8\% variations of PMV can be explained by the supply air temperature (Figures 9 and 14); 65.7\% variations of $\Delta T$ can be explained by the supply air temperature (Figures 10 and 15); and 70.2\% variations of EUC can be explained by the supply vane angle (Figures 11 and 16). Thus, all the ventilation performances can be well maintained by properly controlling the corresponding most important operation parameters.

Furthermore, the variations of the ventilation performances caused by the combined effects with the fixed and variable inside surface temperatures of exterior envelope are compared. The combined effects with the fixed inside surface temperature of exterior envelope refers to the combined effects of the three controllable operation parameters, and the combined effects with the variable inside surface temperature of exterior envelope refers to the combined effects of the four operation parameters (Section 3.3). For example, the combined effects with the fixed inside surface temperature of exterior envelope can cause LMAA to vary from $650 \mathrm{~s}$ to $1531 \mathrm{~s}$, while the combined effects with the variable inside surface temperature of exterior envelope can cause LMAA to vary from $649 \mathrm{~s}$ to $1532 \mathrm{~s}$ (Figure 12). Thus, the variations of LMAA caused by the combined effects with the fixed inside surface temperature of exterior envelope overlap $99.8 \%$ of the variations of LMAA caused by the combined effects with the variable inside surface temperature of exterior envelope. In other words, the inside surface temperature of exterior envelope can explain the variations of LMAA by $0.2 \%$. This indicates that the outdoor weather condition is insignificant to LMAA. Similarly, Figures 13-16 show that the inside surface temperature of exterior envelope 
can explain the variations of CRE, PMV, $\Delta$ Tand EUC by $3.9 \%, 18.5 \%, 12.7 \%$ and $20.8 \%$ respectively. Thus, the outdoor weather condition is also insignificant to these ventilation performances. As a result, once the controllable operation parameters are properly determined, the variations of the outdoor weather condition should not significantly affect the ventilation performances. However, it should be noted that, as shown in Figures 14 and 15, the variations of the outdoor weather condition might cause an indoor thermal environment from comfort to discomfort.

Based on the above results, a control strategy is proposed to simplify the operation of stratum ventilation for heating applications as follows. Under a certain outdoor weather condition (e.g., $13.5^{\circ} \mathrm{C}$ or normalized value of 0.5 of the inside surface temperature of exterior wall), the supply airflow rate is determined to be the maximal value (e.g., $0.04 \mathrm{~m}^{3} / \mathrm{s}$ or normalized value of 1 in Figure 6) to minimize LMAA. The supply vane angle is determined to be the middle value (e.g., $35^{\circ}$ or normalized value of 0.5 in Figures 7 and 11) to maximize the ventilation performances regarding CRE and EUC. With the determined supply vane angle and supply airflow rate, the supply air temperature is determined to limit PMV and $\Delta T$ at comfort level (e.g., $26^{\circ} \mathrm{C}$ or normalized value of 0.5 in Figures 9 and 10) [28]. When the outdoor weather condition varies, the controllable operation parameters can be maintained invariable as long as PMV and $\Delta T$ are thermally acceptable. If PMV and/or $\Delta T$ are outside the thermal comfort zone [28] caused by the variations of the outdoor weather condition, the supply air temperature is recommended to be adjusted to transfer PMV and/or $\Delta T$ from thermal discomfort to thermal comfort. This is because PMV and $\Delta T$ are most sensitive to the supply air temperature. Thus, to accommodate the variations of the outdoor weather condition, a constant-air-volume system capable of adjusting the supply air temperature is preferable to a variable-air-volume system with a constant supply air temperature. In summary, the supply airflow rate and the supply vane angle are recommended to be maintained at the maximal value (e.g., $0.04 \mathrm{~m}^{3} / \mathrm{s}$ ) and middle value (e.g., $35^{\circ}$ ) respectively for high indoor air quality and energy efficiency, and the supply air temperature is determined according to the outdoor weather condition for 
thermal comfort.

It is noted that the proposed operation strategy does not aim to optimize the ventilation performances, but to simplify the operation while providing reasonable ventilation performances. Sensitivity analysis (i.e., the analysis of the individual effects and combined effects) is one of the widely used methods to provide guidelines to improve the design and operation performances [50]. However, sensitivity analysis is not an optimization method $[50,55]$. The comprehensive optimization method considering different operation performances needs to be developed in future studies. The optimization method firstly should be able to balance the different ventilation performances reasonably. Table 4 indicates that the ventilation performances can be conflicting with each other. Moreover, since there are a large number of operation alternatives (different combinations of the supply vane angle, supply airflow rate and supply air temperature) for different outdoor weather conditions, the optimization method should be computationally efficient.

\section{Conclusions}

CFD simulations are conducted to study the effects of the operation parameters on the performances of stratum ventilation for heating applications. Experiments are conducted to validate the CFD simulations. Using the experimentally validated CFD simulations, both the individual effects and combined effects of the supply vane angle, supply airflow rate, supply air temperature and inside surface temperature of exterior envelope on the ventilation performances are analyzed. The individual effects show that the supply vane angle is most important to both CRE and EUC, the supply airflow rate is most important to LMAA, and the supply air temperature is most important to both PMV and $\Delta T$. The comparisons of the individual and combined effects show that the variations of LMAA, CRE, PMV, $\Delta T$ and EUC caused by the combined effects of the four operation parameters can be explained by the corresponding most important operation parameters by $86.5 \%, 85.6 \%, 78.8 \%, 65.7 \%$ and $70.2 \%$ respectively. Moreover, the outdoor weather condition does not 
significantly affect LMAA, CRE and EUC, but can transfer PMV and $\Delta T$ to discomfort level.

Furthermore, the constant-air-volume system is recommended for heating applications of stratum ventilation. In practice, the supply airflow rate and the supply vane angle are suggested to be set at the maximal value and middle value respectively for high indoor air quality and energy efficiency, and the supply air temperature is modulated according to the outdoor weather condition for thermal comfort. This proposed control strategy simplifies the operation of stratum ventilation for heating applications.

\section{Acknowledgment}

The work presented in this paper is financially supported by National Natural Science Foundation of China (Grant No. 51608066; Grant No. 51878585) and the Fundamental Research Funds for the Central Universities (Project No. 2018CDXYCH0015). We also thank Ruiduan Han for his work in the experiments.

\section{References}

[1] Cao G, Awbi H, Yao R, Fan Y, Sirén K, Kosonen R, Zhang JJ. 2014. A review of the performance of different ventilation and airflow distribution systems in buildings. Building and Environment, 73, 171-186.

[2] Lin Z, Chow TT, Tsang CF, Fong KF, Chan LS. 2009. Stratum ventilation - a potential solution to elevated indoor temperatures. Building and Environment, 44(11), 2256-2269.

[3] Cheng Y, Lin Z, Fong AM. 2015. Effects of temperature and supply airflow rate on thermal comfort in a stratum-ventilated room. Building and Environment, 92, 269-277.

[4] Lin Z, Yao T, Chow TT, Fong KF, Chan LS. 2011. Performance evaluation and design guidelines for stratum ventilation. Building and Environment, 46(11), 2267-2279. 
[5] Fong ML, Lin Z, Fong KF, Chow TT, Yao T. 2011. Evaluation of thermal comfort conditions in a classroom with three ventilation methods. Indoor Air, 21(3), 231-239.

[6] Lin Z, Lee CK, Fong S, Chow TT, Yao T, Chan ALS. 2011. Comparison of annual energy performances with different ventilation methods for cooling. Energy and Buildings, 43(1), 130-136.

[7] Fong KF, Lee CK, Lin Z. 2019. Investigation on effect of indoor air distribution strategy on solar air-conditioning systems. Renewable Energy, 131, 413-421.

[8] Zhang S, Cheng Y. 2017. Performance improvement of an ejector cooling system with thermal pumping effect (ECSTPE) by doubling evacuation chambers in parallel. Applied Energy, 187, 675-688.

[9] Zhang S, Sun Y, Cheng Y, Huang P, Oladokun MO, Lin Z. 2018. Response-surface-model-based system sizing for Nearly/Net zero energy buildings under uncertainty. Applied Energy, 228, 1020-1031.

[10]Lin Z. 2017. Stratum ventilation-a low-carbon way to thermal comfort and indoor air quality. International Journal of Low-Carbon Technologies, 12(3), 323-329.

[11]Huan C, Wang FH, Lin Z, Wu XZ, Ma ZJ, Wang ZH, Zhang LH. 2016. An experimental investigation into stratum ventilation for the cooling of an office with asymmetrically distributed heat gains. Building and Environment, 110, 76-88.

[12]Tian L, Lin Z, Liu J, Yao T, Wang Q. 2011. The impact of temperature on mean local air age and thermal comfort in a stratum ventilated office. Building and Environment, 46(2), 501-510.

[13]Zhang S, Cheng Y, Huan C, Lin Z. 2018. Modeling non-uniform thermal environment of stratum ventilation with supply and exit air conditions. Building and Environment, 144, 542-554.

[14]Zhang S, Cheng Y, Fang Z, Huan C, Lin Z. 2017. Optimization of room air temperature in stratum-ventilated rooms for both thermal comfort and energy saving. Applied Energy, 204, 420-431.

[15]Zhang S, Cheng Y, Huan C, Lin Z. 2018. Heat removal efficiency based 
multi-node model for both stratum ventilation and displacement ventilation. Building and Environment, 143, 24-35.

[16]Zhang S, Cheng Y, Huan C, Lin Z. 2018. Equivalent room air temperature based cooling load estimation method for stratum ventilation and displacement ventilation. Building and Environment, https://doi.org/10.1016/j.buildenv.2018.10.057.

[17]Zhang S, Cheng Y, Fang Z, Lin Z. 2018. Dynamic control of room air temperature for stratum ventilation based on heat removal efficiency: Method and experimental validations. Building and Environment, 140, 107-118.

[18] Shao X, Wang K, Li X, Lin Z. 2018. Potential of stratum ventilation to satisfy differentiated comfort requirements in multi-occupied zones. Building and Environment, 143, 329-338.

[19]Zhang S, Cheng Y, Oladokun MO, Lin Z. 2018. Subzone control method of stratum ventilation for thermal comfort improvement. Building and Environment, in Press.

[20]Cheng Y, Zhang S, Huan C, Oladokun MO, Lin Z. 2019. Optimization on fresh outdoor air ratio of air conditioning system with stratum ventilation for both targeted indoor air quality and maximal energy saving. Building and Environment, $147,11-22$.

[21]Cheng Y, Li B, Fang Z. 2017. Impact of air supply angle on heating performance of stratum ventilation in winter arranged on the same side as air supply/return terminals. Building Science, 33(10), 120-127. (in Chinese)

[22]Cheng Y, Lin Z. 2016. Experimental investigation into the interaction between the human body and room airflow and its effect on thermal comfort under stratum ventilation. Indoor Air, 26(2), 274-285.

[23] Yao T, Lin Z. 2014. An experimental and numerical study on the effect of air terminal layout on the performance of stratum ventilation. Building and Environment, 82, 75-86.

[24]Ye X, Kang Y, Zuo B, Zhong K. 2017. Study of factors affecting warm air spreading distance in impinging jet ventilation rooms using multiple regression 
analysis. Building and Environment, 120, 1-12.

[25]Ai ZT, Mak CM. 2016. Short-term mechanical ventilation of air-conditioned residential buildings: A general design framework and guidelines. Building and Environment, 108, 12-22.

[26]Krajčík M, Simone A, Olesen BW. 2012. Air distribution and ventilation effectiveness in an occupied room heated by warm air. Energy and Buildings, 55, 94-101.

[27]Cheng Y, Fong ML, Yao T, Lin Z, Fong KF. 2014. Uniformity of stratum ventilated thermal environment and thermal sensation. Indoor Air, 24(5), 521-532.

[28]ASHRAE 55. 2017. Thermal environmental conditions for human occupancy, ASHRAE Standard 55- 2013. American Society of Heating, Refrigerating and Air-conditioning Engineers, Atlanta, Georgia.

[29]ISO. 7730: 2005. Ergonomics of the thermal environment-Analytical determination and interpretation of thermal comfort using calculation of the PMV and PPD indices and local thermal comfort criteria.

[30] Awbi HB. 2007. Ventilation systems: Design and performance. Taylor \& Francis.

[31] Yuan X, Chen Q, Glicksman LR. 1999. Measurements and computations of room air flow with displacement ventilation. ASHRAE Transactions, 105(1), 340-352.

[32] Ahmed AQ, Gao S, Kareem AK. 2016. A numerical study on the effects of exhaust locations on energy consumption and thermal environment in an office room served by displacement ventilation. Energy Conversion and Management, $117,74-85$.

[33]Chen Q. 2009. Ventilation performance prediction for buildings: a method overview and recent publications. Building and Environment, 44(4), 848-858.

[34] Shao X, Li X, Ma X, Zhu F. 2017. Long-term prediction of dynamic distribution of passive contaminant in complex recirculating ventilation system. Building and Environment, 121, 49-66.

[35]Zhou Y, Deng Y, Wu P, Cao SJ. 2017. The effects of ventilation and floor heating 
systems on the dispersion and deposition of fine particles in an enclosed environment. Building and Environment, 125, 192-205.

[36]Rahmati B, Heidarian A, Jadidi AM. 2018. Investigation in performance of a hybrid under-floor air distribution with improved desk displacement ventilation system in a small office. Applied Thermal Engineering, 138, 861-872.

[37] Kosutova K, Hooff T, Blocken B. 2018. CFD simulation of non-isothermal mixing ventilation in a generic enclosure: impact of computational and physical parameters. International Journal of Thermal Sciences, 129, 343-357.

[38] Airpak 3.0 User's Guide, Fluent Inc., Lebanon, US, 2007.

[39]ANSYS Inc. 2013. ANSYS Fluent Theory Guide, Canonsburg, PA.

[40]Cheng Y. 2015. Experimental and numerical study of air distribution characteristics and thermal environment under stratum ventilation. Ph.D. Dissertation, City University of Hong Kong.

[41]Cheng Y, Lin Z. 2015. Technical feasibility of a stratum-ventilated room for multiple rows of occupants. Building and Environment, 94, 580-592.

[42]Heiselberg P. 1994. Draught risk from cold vertical surfaces. Building and Environment, 29(3), 297-301.

[43] Manz H, Frank T. 2004. Analysis of thermal comfort near cold vertical surfaces by means of computational fluid dynamics. Indoor and Built environment, 13(3), 233-242.

[44] Tominaga Y, Stathopoulos. 2007. Turbulent Schmidt numbers for CFD analysis with various types of flow field. Atmospheric Environment, 41(37), 8091-8099.

[45]Li X, Li D, Yang X, Yang J. 2003. Total air age: an extension of the air age concept. Building and Environment, 38(1), 1263-1269.

[46]Zhang S, Huang P, Sun Y. 2016. A multi-criterion renewable energy system design optimization for net zero energy buildings under uncertainties. Energy, 94, 654-665.

[47]He S, Li Y, Wang RZ. 2009. A new approach to performance analysis of ejector refrigeration system using grey system theory. Applied Thermal 
Engineering, 29(8-9), 1592-1597.

[48]Rasouli M, Ge G, Simonson CJ, Besant RW. 2013. Uncertainties in energy and economic performance of HVAC systems and energy recovery ventilators due to uncertainties in building and HVAC parameters. Applied Thermal Engineering, 50(1), 732-742.

[49]Sun Y. 2015. Sensitivity analysis of macro-parameters in the system design of net zero energy building. Energy and Buildings, 86, 464-477.

[50]Tian W. 2013. A review of sensitivity analysis methods in building energy analysis. Renewable and Sustainable Energy Reviews, 20, 411-419.

[51]Taghinia JH, Rahman MM, Lu X. 2018. Effects of different CFD modelling approaches and simplification of shape on prediction of flow field around manikin. Energy and Buildings, 170, 47-60.

[52]Melikov A, Popiolek Z, Silva MCG, Care I, Sefker T. 2007. Accuracy limitations for low-velocity measurements and draft assessment in rooms. HVAC\&R Research, 13(6), 971-986.

[53]Lam JC, Wan KK, Yang L. 2008. Sensitivity analysis and energy conservation measures implications. Energy Conversion and Management, 49(11), 3170-3177.

[54]Coleman HW, Steele WG. 1999. Experimentation and Uncertainty Analysis for Engineers. John Wiley \& Sons, Inc., New York.

[55]Lu Y, Wang S, Yan C, Shan K. 2015. Impacts of renewable energy system design inputs on the performance robustness of net zero energy buildings. Energy, 93, 1595-1606. 


\section{Highlights}

- Experiments of stratum ventilation for heating are used to validate CFD simulations.

- Individual and combined effects of four operation parameters on ventilation performances are analyzed.

- Relative importance of the operation parameters for each ventilation performance is identified

- Ventilation performances are mainly determined by corresponding most important operation parameters.

- Control strategy is proposed to simplify heating operation of stratum ventilation. 